\title{
Mechanical Model for Drift-Induced Punching of Slab- Column Connections without Transverse Reinforcement
}

\author{
by Ioannis-Sokratis Drakatos, Aurelio Muttoni, and Katrin Beyer
}

\begin{abstract}
A mechanical model is presented for predicting the momentrotation relationship of interior slab-column connections without transverse reinforcement when subjected to seismically induced drifts. The model accounts explicitly for the three load-transfer actions between slab and column contributing to the unbalanced moment resistance-that is, eccentric shear, flexure, and torsion. The moment resistance and deformation capacity are deduced from the intersection of the moment-rotation curve with a failure criterion that is based on the Critical Shear Crack Theory and distinguishes between monotonic and cyclic loading conditions. The model predicts both the moment resistance and the deformation capacity of tests found in the literature well. Based on the model predictions, it is shown that the rotation capacity of slab-column connections in flatslab systems decreases with increasing gravity load and increasing effective depth. Larger column size to effective depth ratios lead to increased rotation capacity while the top reinforcement ratio has little influence on the rotation capacity. It is also shown that cyclic loading results in smaller rotation capacities than monotonic loading, which is more pronounced for small gravity loads.
\end{abstract}

Keywords: Critical Shear Crack Theory; eccentric punching; flat slab; interstory drift; moment transfer; slab-column connections.

\section{INTRODUCTION}

The structural system of reinforced concrete flat slabs (two-way slabs without beams) is widely used in building construction during the last decades, as it offers significant advantages to all involved stakeholders (owners, engineers, architects, constructors), such as large open spaces, reduced story heights, simplified formwork, reduced construction time, and cost. Although slab-column systems are not expected to contribute to the lateral resistance of the structure due to their low horizontal stiffness, the slab-column connection must have the capacity to follow the seismically induced lateral displacements of the building while maintaining the capacity to transfer the vertical loads from the slab to the columns. Otherwise, brittle punching failure of the slab may occur and the deformation capacity of the entire building is limited by the deformation capacity of the slabcolumn connection if the building is not designed to resist progressive collapse.

When a slab-column connection is subjected to a combination of unbalanced moment and shear force, three different slab actions are contributing to the moment resistance ${ }^{1}$ (Fig. 1): 1) eccentric shear force, 2) flexure; and 3) torsion. As soon as the behavior of the slab-column connection subjected to an unbalanced moment becomes nonlinear, it is rather difficult to obtain an accurate and realistic estimation of the contribution of the different resisting mechanisms to the overall capacity of the slab-column connection. This is

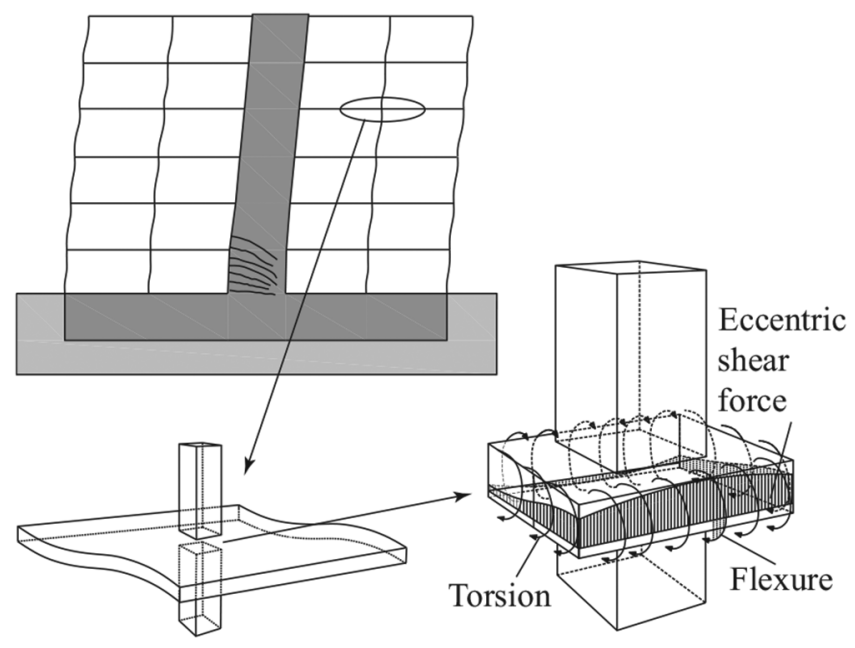

Fig. 1-Internal actions in vicinity of column for vertical loading and inserted moment due to earthquake-type loading according to theory of elasticity.

accentuated by the fact that the aforementioned resistance mechanisms are associated with different failure modes.

The ACI $318-14^{2}$ Building Code provisions for the design of slab-column connections to resist seismically induced drifts are currently based on a simplified eccentric sheartransfer model for moment capacity and on an empirical relationship for deformation capacity. Punching failure for a flat slab without transverse reinforcement due to vertical load alone (concentric punching) occurs when the shear force at the control perimeter (assumed at a distance $d / 2$ from the column face) reaches a critical value. When designing for a combination of vertical load and unbalanced moment, the latter is considered to be transferred partly by the eccentric shear force and partly by flexure. To compute the moment capacity, punching failure is assumed to occur when the maximum shear stress due to the vertical load (assumed to be constant along the control perimeter) and due to the unbalanced moment (assumed to vary linearly along the control perimeter faces that are subjected to torsion [Fig. 1]) reaches the same limit value as for concentric punching $\left(0.33 \sqrt{ } f_{c}\right.$ for $f_{c}$ in $\mathrm{MPa}\left[4 \sqrt{ } f_{c}\right.$ for $f_{c}$ in psi]). The deformation capacity is estimated using an empirical relationship that is based on the work by Pan and Moehle, ${ }^{3}$ which links the drift capacity to the gravity-induced load. No calculation of induced moments

ACI Structural Journal, V. 115, No. 2, March 2018.

MS No. S-2017-033.R3, doi: 10.14359/51701110, was received April 12, 2017, and reviewed under Institute publication policies. Copyright (C) 2018, American Concrete Institute. All rights reserved, including the making of copies unless permission is obtained from the copyright proprietors. Pertinent discussion including author's closure, if any, will be published ten months from this journal's date if the discussion is received within four months of the paper's print publication. 
is required when computing the deformation capacity. The provisions for the design of slab-column connections in the presence of seismic moments according to ACI $318-14^{2}$ are presented in Appendix 1. ${ }^{*}$ A trilinear relationship between interstory drift and gravity-induced shear has been proposed by Hueste and Wight. ${ }^{4}$ For the same gravity load, it predicts larger drift capacities than the provisions by ACI $318-14 .^{2}$

In 2009 , Broms ${ }^{5}$ proposed a model for calculating the critical connection rotation that leads to punching failure. Broms assumes that punching occurs when the concrete compression strain in the tangential direction at the column face reaches a critical value that depends on the height of the compression zone and the concrete compressive strength. Broms' method provides only estimates of rotation and moment at failure and not the entire moment-rotation relationship. In addition, Broms' model is limited to slab-column connections subjected to monotonic loading only.

In this article, a mechanical model is proposed for computing the entire moment-rotation relationship of slab-column connections subjected to seismic loading. This model allows for the computation of the contribution of each resisting mechanism - that is, eccentric shear, flexure, and torsion. To do so, the slab is divided into $n$ sector elements and equilibrium is first formulated for each sector element and then for the entire slab. This permits the connection of local deformations of each sector element to the global rotation of the slab-column connection. The presented approach considers, in a first step, the slab region until $0.22 L$ from the column axis (defined as slab-column connection region, $L$ corresponds to the distance from midspan to midspan). In a second step, it can be combined with an effective beam width model for the slab region outside $0.22 L$ to transform the connection rotation to the interstory drift. Drift-induced punching failure is determined by combination of the proposed model for computing the moment-rotation relationship with the failure criterion of the Critical Shear Crack Theory ${ }^{6}$ (CSCT). The failure criterion distinguishes between monotonic loading, for which shear stress redistribution between sector elements is considered, and cyclic loading, for which shear stress redistribution is neglected.

\section{RESEARCH SIGNIFICANCE}

ACI 318-14 2 adopts different approaches for calculating the unbalanced moment capacity of a slab-column connection and its deformation capacity under seismic actions. The influence of cyclic loading on the deformation capacity is accounted for empirically, while its influence on the moment capacity is overlooked. Therefore, there is a need for a mechanical model that correctly predicts the unbalanced moment, the corresponding connection rotation, and the deformation capacity accounting for cyclic loading conditions.

\footnotetext{
*The Appendix is available at www.concrete.org/publications in PDF format, appended to the online version of the published paper. It is also available in hard copy from ACI headquarters for a fee equal to the cost of reproduction plus handling at the time of the request.
}

\section{SLAB DEFORMATION RELATED TO INTERSTORY DRIFT}

For evaluating the seismic performance of buildings in terms of displacements, structural engineers typically use the interstory drift $\psi_{s t}$-that is, the relative horizontal displacement between two adjacent floors divided by the story height. In structural systems of flat slabs and columns, the deformation of the slab and the column both contribute to the interstory drift

$$
\psi_{s t}=\psi_{c o l}+\psi_{\text {slab }}
$$

where $\psi_{c o l}$ and $\psi_{s l a b}$ are the contributions of column deformation and slab deformation to the interstory drift, respectively.

In laboratory tests, the specimen size is often limited to the hogging moment area under gravity loads. It is usually assumed that the limit of this area is located at a distance of $r=0.22 L$ from the column axis, ${ }^{7}$ where $L$ is the midspanto-midspan distance. In reality, the slab region inside and outside $r=0.22 \mathrm{~L}$ are contributing to the rotation due to slab deformation

$$
\psi_{s l a b}=\psi_{s c c}+\psi_{o s}
$$

where $\psi_{s c c}$ and $\psi_{o s}$ are the rotation due to the deformation of the slab-column connection (defined as slab region inside $r=0.22 L$ ) and the rotation due to the deformation of the outer portion of the slab (outside $r=0.22 L$ up to $r=0.50 L$ ), respectively.

To assess the contribution of $\psi_{s c c}$ and $\psi_{o s}$ to the slab deformation $\psi_{\text {slab }}$, a slab element with continuity boundary conditions and subjected to horizontal loads was analyzed using the finite element program SAP2000 $\left(\mathrm{CSI}^{8}\right)$. Continuity was provided through restraining of the slab edges parallel to the lateral force against rotation about an axis parallel to the edge while the slab edges perpendicular to the lateral force were constrained to have equal deflections and rotations about an axis parallel to the edge. The contribution of each component is the rotation at the central node of the slab-column connection after the assignment of rigid body conditions to all remaining components. In this model, the column is modeled by a rigid beam element and the slab by layered shell elements to which nonlinear material laws are assigned. The layered shell formulation adopted for the numerical modeling uses smeared reinforcement. The analysis is nonlinear static and yields the moment-rotation relationship due to flexural deformations of the slab but cannot account for punching failure. Details with respect to the numerical modeling can be found in Appendix 2 . Figure 2 illustrates both contributions $\psi_{s c c}$ and $\psi_{o s}$ to the slab rotation $\psi_{\text {slab }}$ for a flexural reinforcement ratio of $1.50 \%$ in the hogging moment area. Because the model captures only flexural failure, Fig. 2 also shows horizontal lines that correspond to the moment at punching failure according to ACI 318-14. ${ }^{2}$ For this horizontal load level, the slab-column connection rotation $\psi_{s c c}$ contributes approximately $75 \%$ to $80 \%$ to the total slab rotation $\psi_{\text {slab }}$, the remaining part being contributed by the slab region outside $r=0.22 L$. 


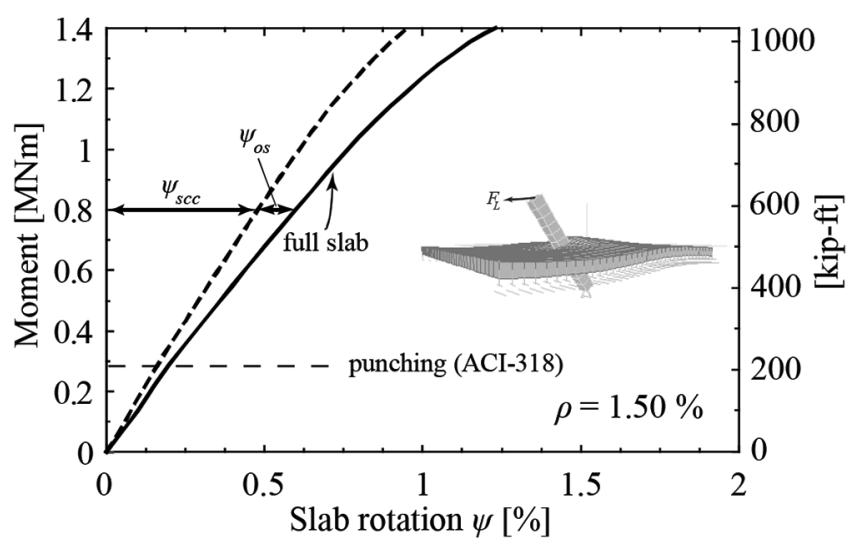

Fig. 2-Contribution of slab deformation inside and outside $\mathrm{r}=0.22 \mathrm{~L}$ to interstory drift for flexural reinforcement ratio equal to $1.50 \%(\mathrm{~L}=6.8 \mathrm{~m}, \mathrm{~h}=0.25 \mathrm{~m}, \mathrm{c}=0.39 \mathrm{~m}$, column assumed to be very stiff). (Note: $1 \mathrm{~m}=3.28 \mathrm{ft}$.)

\section{Contribution of slab-column connection to slab deformation}

This section analyzes characteristics of the slab deformations inside $0.22 L$ using the SAP2000 analysis presented in the previous section. When a slab-column connection is subjected to an unbalanced moment, the local slab rotations vary along the perimeter $r=0.22 L$. The location of the investigated points is described by the angle $\varphi$, which is measured with regard to the bending axis $y$ (Fig. 3(a)). Figure 3(a) shows the variation of the slab rotation with $\varphi$ for vertical loads alone (black line) and for three different horizontal load levels (colored lines). When only vertical loads are applied, the system is approximately axis-symmetric and the slab rotation is almost constant. When an unbalanced moment about the y-axis is introduced, the slab rotation varies with $\varphi$ and the relationship between maximum local slab rotation (for $\varphi=\pi / 2$ ) and minimum slab rotation (for $\varphi$ $=3 \pi / 2$ ) follows approximately a sinusoidal law. This observation has been confirmed experimentally for slab-column connections subjected to constant shear force and increasing moment (Drakatos et al. ${ }^{7}$ ). This relationship will be assumed in the mechanical model to connect the local slab rotations to the global rotation of the slab-column connection.

Figure 3(b) shows the profile of slab deflections along the $\mathrm{x}$-axis for the same load levels as in Fig. 3(a). It shows that the profile of slab deflections is approximately linear between $r$ $=d$ (slab effective depth) and $r=0.22 L$. This means that the curvature in radial direction of the slab-column connection in the region $r>d$ can be neglected. The assumption of a rigid behavior of this region ${ }^{6,9}$ is thus also confirmed for the case of slab-column connections with unbalanced moment.

\section{Contribution of slab region outside $0.22 L$ to slab deformation}

The slab part outside $r=0.22 L$ contributes approximately a quarter to the total slab rotation (dashed-dotted lines, Fig. 2). To estimate this contribution using a simple mechanical approach, an effective beam width model is employed. In this model, the column is modeled as rigid but with its actual dimensions. The slab is modeled by a beam to which a width $\alpha l_{2}$ is assigned, where $l_{2}$ is the transverse span. ${ }^{10}$ The
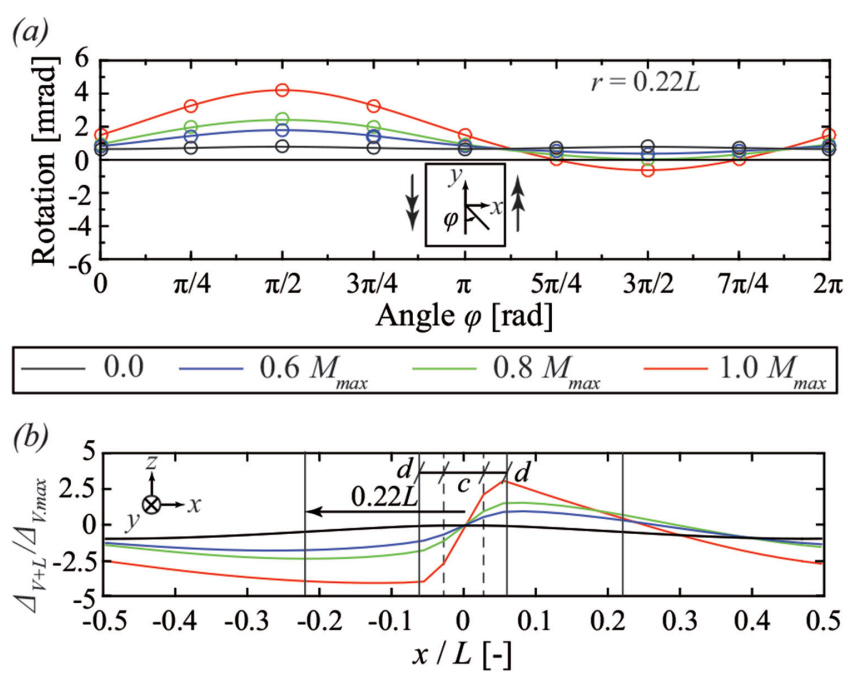

Fig. 3-(a) Local slab rotations at varying angles; and (b) slab deflections along $x$-axis for different lateral load levels.

width reduction coefficient $\alpha$ can be derived assuming the same rotational stiffness for the full-width slab (real system) and the equivalent beam (fictitious system)

$$
\alpha=\frac{M}{\Psi_{\text {slab }}} \cdot \frac{l_{1}}{l_{2}} \cdot \frac{1}{E_{c} \cdot h^{3}}
$$

where $M$ is the moment transferred to the slab-column connection; $l_{1}$ is the distance between columns (equal to $L) ; E_{c}$ is the modulus of elasticity of concrete; and $h$ is the slab thickness. The slab rotation $\psi_{o s}$ is then obtained from a simple beam model where the column and the slab inside $r$ $=0.22 \mathrm{~L}$ are modeled as rigid. The slab outside $r=0.22 \mathrm{~L}$ is modeled as an elastic beam with a width $\alpha l_{2}$ and height $h$. For the calculation of the reduction coefficient $\alpha$ (Eq. (3)), the unbalanced moment $M$ and the corresponding rotation due to slab deformation $\psi_{\text {slab }}$ are obtained from the moment-rotation relationship of the slab-column connection, which is presented in the next section. Note that cracking is directly accounted for by the width reduction coefficient $\alpha$. For the validation, $M$ and $\psi_{\text {slab }}$ were taken from the layered shell element model and the rotation $\psi_{o s}$, which was obtained by the effective beam model, was compared to that of the finite element model (Fig. 2). The difference in rotations was smaller than $10 \%$.

The slab outside $r=0.22 \mathrm{~L}$ also has an effect on the moment capacity by providing a confining effect. ${ }^{11-13}$ This is, however, not considered in the analytical model presented in this paper.

\section{MOMENT-ROTATION RELATIONSHIP}

This section presents the theoretical background of the proposed model for the moment-rotation relationship of a slab-column connection subjected to a seismically induced moment. The model is derived from the axisymmetric model developed by Kinnunen and Nylander ${ }^{9}$ and Muttoni ${ }^{6}$ for slabs subjected to gravity loads. In the original model, the slab is divided into an even number $n$ of sector elements and the region inside the shear crack. Because that model is 
axisymmetric, the equilibrium formulation can be reduced to one sector element. For the case of a seismically induced moment, several modifications of the axisymmetric analytical model are introduced, which are presented first. Next, equilibrium is formulated for a sector element and then for the entire slab specimen until $r=0.22 L$. It follows the approach for computing the slab-column connection rotation. To compute the total slab rotation, also the deformation of the slab part outside $r=0.22 \mathrm{~L}$ needs to be considered, which is presented in the final part of this section.

\section{Assumptions}

As already shown in Fig. 3(a), the slab rotation of the sector elements follows approximately a sinusoidal law with regard to the location described by angle $\varphi$. The slab rotation of the sector element at angle $\varphi$ with regard to the bending axis $y$ is therefore

$$
\psi(\varphi)=\frac{\psi_{\max }+\psi_{\min }}{2}+\frac{\psi_{\max }-\psi_{\min }}{2} \sin (\varphi)
$$

where $\psi_{\max }$ and $\psi_{\min }$ are the maximum slab rotation for $\varphi=$ $\pi / 2$ and the minimum slab rotation for $\varphi=3 \pi / 2$, respectively.

Moreover, experimental evidence shows that radial curvatures concentrate in the slab area between column axis and shear cracks. ${ }^{6}$ In case of slab-column connections with unbalanced moment $M$, tests by Drakatos et al. ${ }^{7}$ showed that the inclination of critical shear cracks depends on the ratio of unbalanced moment $M$ to shear force $V$ (Fig. 4(a) and (b)), subsequently

(a) monotonic

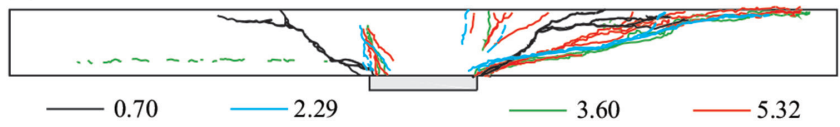

(b) cyclic

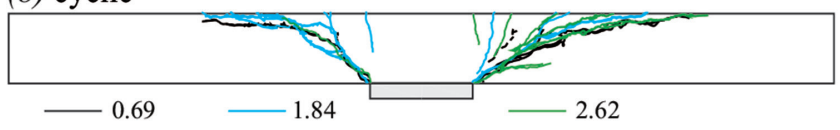

Fig. 4-Critical shear crack inclination for drift-induced punching under: (a) monotonic; and (b) cyclic loading conditions for different ratios of maximum eccentricity to column size (adapted from Drakatos et al. ${ }^{7}$ ).

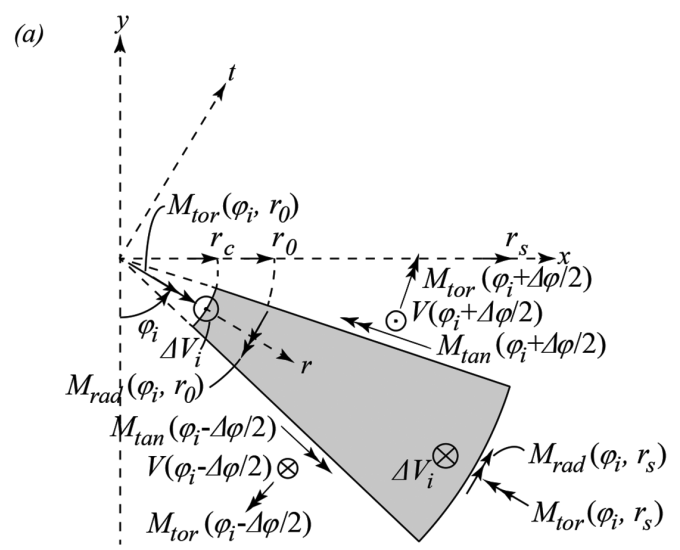

referred to as eccentricity $e$. Based on these observations, it is assumed that the radius $r_{0}$ of the critical shear crack is equal to $e=M / V$, but not smaller than $r_{c}+d($ Reference 6$)$

$$
r_{0}=e \geq r_{c}+d
$$

Past experimental evidence showed that reversed cyclic loading affects the ultimate rotation capacity but does not affect to a significant degree the moment-rotation relationship of slab-column connections before failure. ${ }^{7,14}$ For this reason, the present study assumes that the response envelope under cyclic loading is represented by the monotonic moment-rotation curve.

\section{Equilibrium of sector elements (local level)}

The assumption of different rotations at different angles (Fig. 5(a)) from the bending axis implies that the moment is introduced from the column to the slab not only by a flexural moment but also by a torsional moment and an eccentric shear force. This can be demonstrated by formulating equilibrium for a sector element as shown in Fig. 5.

It is further assumed that no shear transfer occurs between adjacent sector elements. In reality, the shear force will not be zero. However, nonlinear analyses of slab-column connections have shown that the shear flow follows approximately radial lines from the column to the slab perimeter.

Analytical considerations have shown that the torsional curvature at the sector element face $\chi_{t}$ is maximized at the bending axis $(\varphi=0$ and $\varphi=\pi)$ and the column proximity. Tests on slab-column connections ${ }^{7}$ have shown that torsional cracking occurs rather early, resulting in rapid reduction of the torsional rigidity. For this reason, this paper neglects the moments $M_{\text {tor }}(\varphi-\Delta \varphi / 2)$ and $M_{\text {tor }}(\varphi+\Delta \varphi / 2) . M_{\text {tan }}(\varphi-$ $\Delta \varphi / 2)$ and $M_{\text {tan }}(\varphi+\Delta \varphi / 2)$ are the integrals of the tangential moments at the faces of each sector element (Fig. 5(a)). These moments can be determined directly as a function of the assumed rotation and a quadrilinear moment-curvature relationship ${ }^{6}$

$$
\begin{aligned}
M_{\text {tan }}(\varphi)= & m_{R}\left\langle r_{y}-r_{0}\right\rangle+E I_{1} \psi(\varphi)\left\langle\ln \left(r_{1}\right)-\ln \left(r_{y}\right)\right\rangle \\
& +E I_{1} \chi_{T S}\left\langle r_{1}-r_{y}\right\rangle+m_{c r}\left\langle r_{c r}-r_{1}\right\rangle \\
& +E I_{0} \psi(\varphi)\left\langle\ln \left(r_{s}\right)-\ln \left(r_{c r}\right)\right\rangle
\end{aligned}
$$

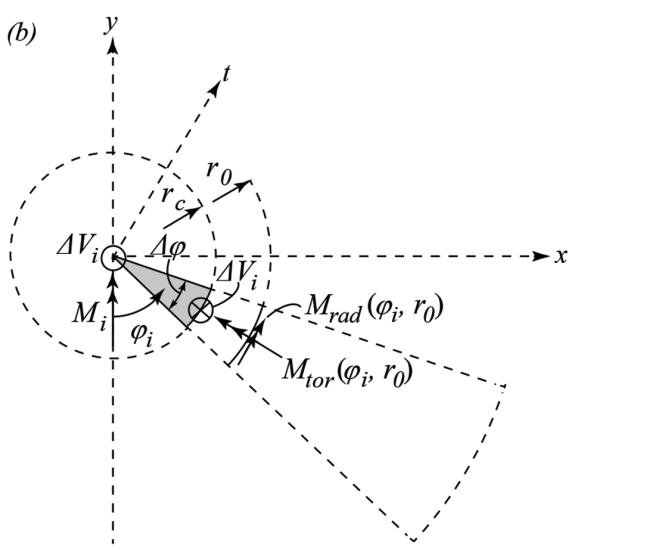

Fig. 5-Internal forces acting on different slab elements: (a) outside shear crack (hogging slab half); and (b) inside shear crack. 
where $E I_{0}$ and $E I_{1}$ are the slab stiffness before and after cracking; $m_{c r}$ and $m_{R}$ are the cracking moment and moment capacity, respectively, per unit width; $\chi_{T S}$ is the curvature due to the tension stiffening effect; and $r_{0}, r_{y}, r_{1}, r_{c r}$, and $r_{s}$ are the radii of the critical shear crack, the yielded zone, the zone in which cracking is stabilized, the cracked zone, and the circular isolated slab element, respectively. The operator $\langle x\rangle$ is $x$ for $x \geq 0$ and 0 for $x<0$. Equation (6) for the calculation of the tangential moment $M_{\text {tan }}(\varphi)$ is taken directly from the analytical model proposed by Muttoni. ${ }^{6}$ For the case of seismically induced deformations, the local slab rotation $\psi$ depends on the angle $\varphi$ of the sector element with regard to the direction of seismic loading and the radius $r_{0}$ of the critical shear crack is updated as a function of the eccentricity (refer to Eq. (5)) to take into account the fact that the shear force becomes less determinant as eccentricity increases. Therefore, the integral of the radial moment for a sector element at angle $\varphi$ and $r=r_{0}$ is

$$
M_{\text {rad }}\left(\varphi, r_{0}\right)=m_{r}(\varphi) r_{0} \Delta \varphi
$$

where $m_{r}(\varphi)$ is the radial moment per unit width at $r=r_{0}$ as function of the radial curvature. ${ }^{6}$

If $\varphi_{i}$ is the angle formed by the axis of bending and the bisector of the $i$-th sector element, the shear force that can be carried by this sector element is derived by moment equilibrium in the radial direction with respect to the center of the column with radius $r_{c}$

$$
\Delta V_{i}=\frac{1}{r_{q}-r_{c}}\left\{M_{\text {rad }}\left(\varphi_{i}, r_{0}\right)-M_{\text {rad }}\left(\varphi_{i}, r_{s}\right)+\left[M_{\tan }\left(\varphi_{i}+\frac{\Delta \varphi}{2}\right)+M_{\tan }\left(\varphi_{i}-\frac{\Delta \varphi}{2}\right)\right] \sin \left(\frac{\Delta \varphi}{2}\right)\right\}
$$

The moment equilibrium in the tangential direction gives the torsional moment that is carried by the connection for the $i$-th sector element

$$
M_{\text {tor }}\left(\varphi_{i}, r_{0}\right)=\left[M_{\text {tan }}\left(\varphi_{i}+\frac{\Delta \varphi}{2}\right)-M_{\text {tan }}\left(\varphi_{i}-\frac{\Delta \varphi}{2}\right)\right] \cos \left(\frac{\Delta \varphi}{2}\right)+M_{\text {tor }}\left(\varphi_{i}, r_{s}\right)
$$

The radial and torsional moments at the perimeter of each sector element $M_{\text {rad }}\left(\varphi_{i}, r_{s}\right)$ and $M_{\text {tor }}\left(\varphi_{i}, r_{s}\right)$ (Eq. (8) and (9), respectively) are obtained using an Effective Beam Width Method, as will be shown in the following section.

Equilibrium of shear forces at the column edge gives the total shear force acting on the connection for the load step $k$

$$
V_{k}=\sum_{i=1}^{n} \Delta V_{i}
$$

Moment equilibrium at the column edge gives the total moment acting on the connection (parallel to the unbalanced moment) for the load step $k$

$$
M_{k}=\sum_{i=1}^{n}\left[M_{r a d}\left(\varphi_{i}, r_{0}\right) \sin \left(\varphi_{i}\right)+M_{t o r}\left(\varphi_{i}, r_{0}\right) \cos \left(\varphi_{i}\right)+\Delta V_{i} r_{c} \sin \left(\varphi_{i}\right)\right]
$$
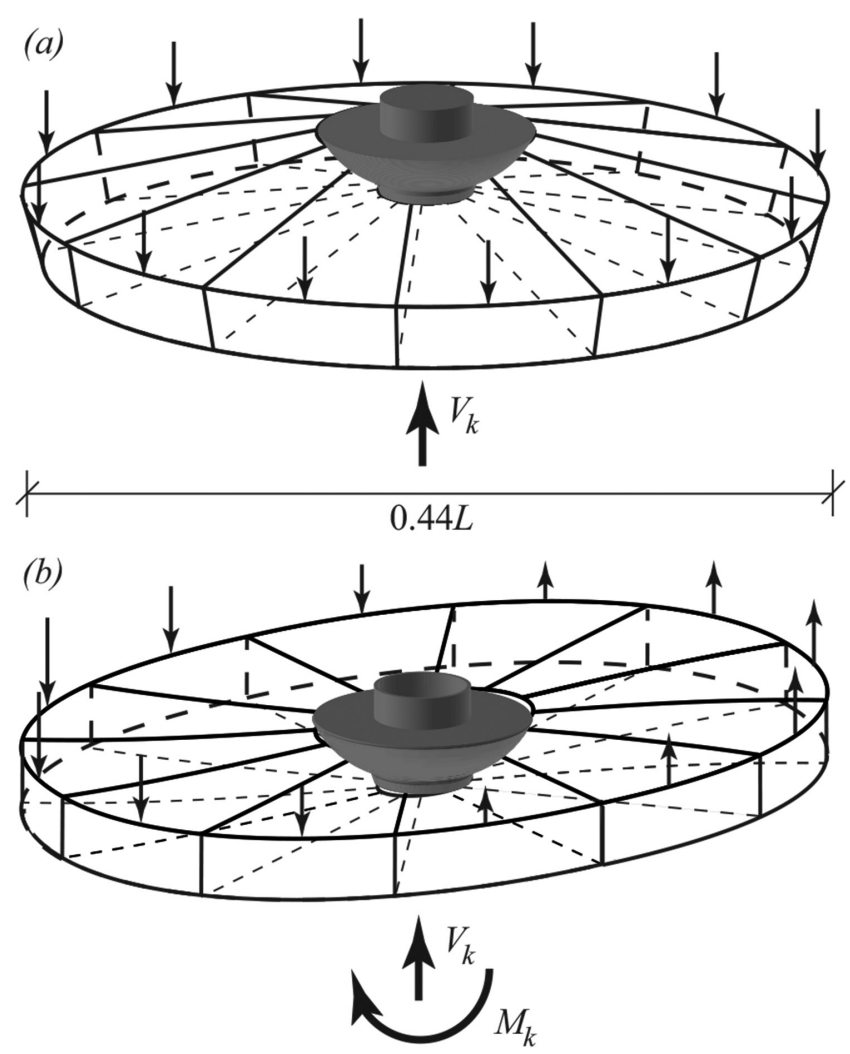

Fig. 6-Assumed deformed shape of slab specimen under: (a) vertical load ${ }^{6}$; and (b) vertical load and imposed lateral deformation.

The three terms of Eq. (11) represent the contribution of flexure, torsion, and eccentric shear force to the total unbalanced moment.

\section{Global equilibrium of slab specimen}

For the case of uniformly distributed vertical loading alone, formulating the equilibrium for one sector element is equivalent to formulating the equilibrium for the entire circular slab because $\psi_{\max }=\psi_{\min }=\psi_{v}$ (Fig. 6(a)). If a seismic moment is added, the slab rotations vary between sector elements and therefore equilibrium has to be formulated locally for each sector element and globally for the entire circular slab (Fig. 6(b)).

The unbalanced moment is applied about the y-axis. The adoption of the kinematic law of Eq. (4) implies symmetry about the $\mathrm{x}$-axis $(\varphi=\pi / 2$ and $\varphi=3 \pi / 2)$ and therefore the moment about the $\mathrm{x}$-axis is always zero. To ensure global equilibrium about the y-axis, the following procedure is adopted: For each load step $k$, a new value of $\psi_{\max }$ is chosen. To determine all local slab rotations by means of the sinusoidal law, one needs to choose a value $\psi_{\min }$, which is iterated such that the sum of all shear forces $\Delta V_{i}$ is equal to the shear force $V$ that is applied to the slab-column connection. The shear force $V$ is assumed as constant because it results from gravity loads. Because lateral loads induce rather insignificant axial forces in interior columns, this assumption is more representative for interior bays. On the other hand, for exterior bays, the axial force variation due to lateral load should be considered, which can be done effectively using the proposed model. To obtain the moment-rotation curve, 

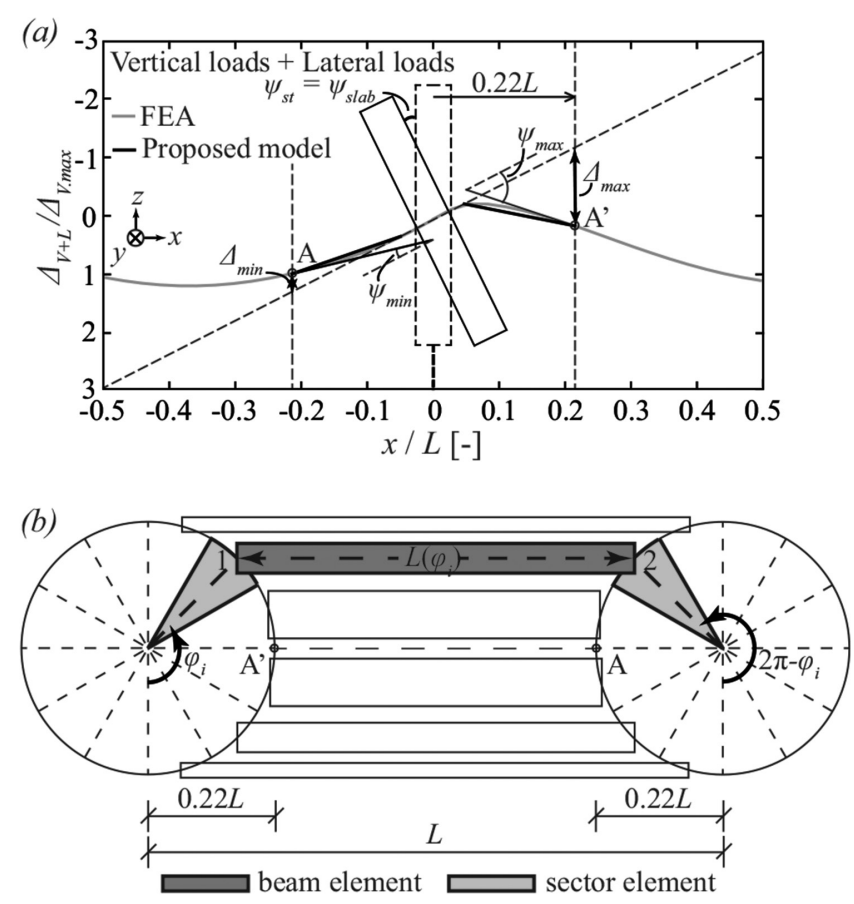

Fig. 7-(a) Deformed shape of slab until midspan according to finite element analysis and proposed model for combined vertical and lateral loads; and (b) Effective Beam Method for calculating contribution of outer slab part to total deformation.

the radius $r_{0}$ of the shear crack is adapted at each load step $k$ as it is assumed to be equal to the attained eccentricity

$$
e_{k}=M_{k} / V_{k}
$$

The aforementioned iterative procedure can also be used if $M_{k}$ or $e_{k}$ rather than $V_{k}$ is constant - that is, situations that can be found when constant horizontal loads act on columns or when slabs with unequal spans are subjected to vertical load alone.

\section{Slab-column connection rotation}

The previous section yields a relationship between the unbalanced moment $M$ and the local slab rotations $\psi(\varphi)$. To determine a relationship between unbalanced moment and slab-column connection rotation $\psi_{s c c}$, a relationship between the local rotations $\psi(\varphi)$ and the connection rotation $\psi_{s c c}$ is needed.

Figure 7(a) shows the deformed shape of the slab analyzed previously until midspan $(0.50 \mathrm{~L})$. Because the proposed model assumes that only the cone inside the shear crack deforms and each element outside the shear crack behaves in the radial direction as a rigid body, the deformed shape of the top slab surface is linear only outside the shear crack (Fig. 6(b)). The connection rotation $\psi_{s c c}$ can be defined using either local slab rotations $\left(\psi_{\text {scc.rot }}\right)$ or local slab deflections $\left(\psi_{\text {scc.deff }}\right)$. If the definition is based on rotations, $\psi_{\text {scc.rot }}$ can be calculated as the average of the maximum and minimum local rotations $\psi_{\max }$ and $\psi_{\min }$ (Fig. 7(a))

$$
\psi_{\text {scc.rot }}=\frac{\Psi_{\max }-\Psi_{\min }}{2}
$$

If the connection rotation $\psi_{\text {scc.def }}$ is computed from deflections, one obtains

$$
\Psi_{\text {scc.defl }}=\frac{\Delta_{\max }-\Delta_{\min }}{2 \Delta r+c}
$$

where $\Delta_{\max }$ and $\Delta_{\min }$ are, respectively, the maximum and minimum local slab deflections at a distance $\Delta r+c / 2=$ $0.22 L$ from the column center along the $\mathrm{x}$-axis (points $\mathrm{A}$ and $\mathrm{A}^{\prime}$ in Fig. 7), where $c$ is the column size. The definition of the slab-column connection rotation with respect to test configurations of previous experimental campaigns on isolated specimens is shown in Appendix 3.

\section{Rotation due to slab deformation outside slab- column connection}

The presented model for the moment-rotation relationship considers only the slab region inside $0.22 L\left(\psi_{s c c}\right)$. To obtain an accurate prediction of the total slab deformation $\psi_{\text {slab }}$, the rotation $\psi_{o s}$ should also be accounted for. This can be performed by calculating the radial and tangential moments $M_{\text {rad }}\left(\varphi_{i}, r_{s}\right)$ and $M_{t o r}\left(\varphi_{i}, r_{s}\right)$ at the perimeter of each sector element. For this purpose, a beam that connects the perimeter of the considered sector element with the perimeter of the sector element of the opposite column (Fig. 7(b)) is used. When the slab is subjected to a rotation $\psi\left(\varphi_{i}\right)$ at Node 1 and $\psi\left(2 \pi-\varphi_{i}\right)$ at Node 2 , the moment at Node 1 can be found using the elastic solution

$$
M_{y, E B W}\left(\varphi_{i}\right)=\frac{2 E I_{k-1}}{L\left(\varphi_{i}\right)}\left[\psi\left(\varphi_{i}\right) \sin \left(\varphi_{i}\right)+\frac{\psi_{\max }-\psi_{\min }}{2}\left(2+\cos ^{2}\left(\varphi_{i}\right)\left(1-3 \frac{r_{c}}{r_{s}}\right)\right)\right]
$$

where the bracketed term represents the projection of the slab rotation to the $y$-axis (perpendicular to the axis of each beam); $L\left(\varphi_{i}\right)$ is the length of the beam that connects the sector element at angle $\varphi_{i}$ with the sector element at angle $2 \pi-\varphi_{i}$; and $E I_{k-1}\left(\varphi_{i}\right)$ is its stiffness calculated using the Effective Beam Width Method

$$
E I_{k-1}=\frac{M_{k-1}}{\psi_{\text {slab. } k-1}} \frac{L\left(\varphi_{i}\right)}{12} \frac{\sin (\Delta \varphi)\left|\sin \left(\varphi_{i}\right)\right|}{4}
$$

where $M_{k-1}$ and $\psi_{\text {slab. } k-1}$ is the unbalanced moment and the total rotation due to slab deformation at the load step k-1. The last fraction of Eq. (16) is inserted so that the sum of the width of all effective beams yields the width of one single effective beam that represents the slab action (Eq. (3) and Appendix 2).

The radial and torsional moments $M_{\text {rad }}\left(\varphi_{i}, r_{s}\right)$ and $M_{\text {tor }}\left(\varphi_{i}, r_{s}\right)$ at the perimeter of each sector element can be found by projecting the moment calculated using Eq. (15) to the radial and tangential direction, respectively

$$
\begin{aligned}
& M_{\text {tor }}\left(\varphi_{i}, r_{s}\right)=M_{y, E B W}\left(\varphi_{i}\right) \cos \left(\varphi_{i}\right) \\
& M_{\text {rad }}\left(\varphi_{i}, r_{s}\right)=M_{y, E B W}\left(\varphi_{i}\right) \sin \left(\varphi_{i}\right)
\end{aligned}
$$




\section{FAILURE CRITERION}

In the following, two failure criteria for drift-induced punching are proposed, which are both based on the failure criterion of the CSCT. ${ }^{6}$ One failure criterion is applied to slabs subjected to monotonic loading and the other to slabs subjected to cyclic loading. The criteria differ with regard to the assumed shear force redistribution. Shear redistribution from sector elements with higher rotations to sector elements with smaller rotations has been previously ${ }^{15}$ found to significantly influence the punching strength and corresponding rotation of slabs loaded and/or reinforced in a non-axisymmetric manner.

For slabs subjected to monotonic loading, it is assumed that failure occurs when the shear force reaches the shear resistance for the hogging slab half. This criterion is denoted by CSCT(mono). For slabs subjected to cyclic loading, shear redistribution is neglected and failure is assumed to occur when the sector subjected to the largest slab rotation reaches the CSCT-failure criterion. This is denoted by CSCT(cyc). In the following, the two failure criteria are described.

The failure criterion CSCT(cyc) applied to cyclically loaded slabs predicts smaller rotation capacities than the failure criterion $\mathrm{CSCT}(\mathrm{mono})$ applied to monotonically loaded slabs. Cyclic loading leads to an accumulation of plastic strains and therefore to an increase in crack opening with each cycle. If symmetric cycles are applied, $\psi_{\min }$ increases with increasing number of cycles. For the same slab rotation $\psi_{s c c}, \psi_{\max }$ is therefore larger and so are the crack widths of the hogging slab half, which in turn lead to a reduced shear force redistribution between adjacent sector elements. To account for this phenomenon implicitly, different failure criteria are applied to monotonically and cyclically loaded slabs. This implicit approach is chosen because the analytical model does not account for the effect of the loading history on the moment-rotation relationship.

\section{Approach accounting for shear stress redistribution (CSCT(mono))}

Based on the work of Sagaseta et al. ${ }^{15}$ on nonaxisymmetric punching, it is assumed that failure of monotonically loaded slabs occurs when the sum of the shear forces acting on the sector elements of the hogging slab half $(0 \leq \varphi \leq \pi)$ is equal to the sum of the shear resistance of these sector elements

$$
V_{R . h o g}=\int_{0}^{\pi} v_{R}(\varphi)\left(r_{c}^{\prime}+d(\varphi)\right) d \varphi
$$

where $r_{c}{ }^{\prime}$ is the nominal radius for shear calculation, which for square columns is adjusted to give the same perimeter (that is, $r_{c}{ }^{\prime}=2 c / \pi$ ), and $v_{R}(\varphi)$ is the shear resistance per unit length in $\mathrm{MN} / \mathrm{m}$

$$
v_{R}(\varphi)=\frac{0.75 d(\varphi) \sqrt{f_{c}^{\prime}}}{1+15 \frac{\psi(\varphi) d(\varphi)}{d_{g}+d_{g .0}}} \text { (SI units; N, mm) }
$$

where $f_{c}$ is the concrete compressive strength; $d_{g}$ is the maximum aggregate size; and $d_{g .0}$ is the reference aggregate size, which is assumed to be equal to $16 \mathrm{~mm}$ (0.63 in.). For imperial units (psi [in.]), the factor 0.75 has to be replaced by 9. Note that the effective depth $d$ changes with $\varphi$ to account for the different effective depths for bending around the $\mathrm{x}-$ and y-axis. One can either apply a cosinusoidal interpolation for intermediate angles or use an average value for all angles. The former is applied for the calculations presented in this paper.

\section{Approach based on maximum rotation (CSCT(cyc))}

In this article, the CSCT(cyc) approach is used for slabs subjected to cyclic moments with increasing amplitude. This approach neglects a possible redistribution of the shear force to adjacent sector elements, which are subjected to smaller rotations than the maximum rotation $\psi_{\max }$. It is assumed that punching failure occurs when the shear force that is carried by the compression strut (that is developed along the shear crack) of the sector element with the maximum rotation $\psi_{\max }$ is equal to the shear resistance of this sector element. According to the CSCT (Muttoni ${ }^{6}$ ), the shear resistance of the sector element subjected to the maximum rotation $\psi_{\max }$ can be computed as

$$
V_{R . \delta / 2}=\frac{0.75 b_{0}(\Delta \varphi) d(\pi / 2) \sqrt{f_{c}^{\prime}}}{1+15 \frac{\psi_{\max } d(\pi / 2)}{d_{g}+d_{g .0}}}(\text { SI units; } \mathrm{N}, \mathrm{mm})
$$

where $b_{0}(\Delta \varphi)$ is the part of the critical section that belongs to the sector element with the maximum rotation. The critical section is assumed to be at a distance of $d / 2$ from the column face. Here again, for $f_{c}$ expressed in psi, the factor 0.75 has to be replaced by 9 .

All calculations presented herein were conducted using 8, 16 , and 32 sector elements and no difference was observed in the obtained results. The choice of 16 sector elements (that is, $\Delta \varphi=22.5$ degrees) is optimal, as it fits rather well with radial cracking patterns from experiments and is not computationally too expensive.

\section{VALIDATION OF PROPOSED MODEL}

The proposed model is compared to tests on slab-column connections under combined vertical load and increasing moment that are reported in the literature. Each test campaign measured the slab-column rotation differently. Appendix 3 outlines for each campaign how the measured quantities are estimated with the analytical model. More information on the selected tests is provided in Appendix 4 (Tables 1, ${ }^{7,16-20} 2,,^{7,19,21-35}$ and 3; tests under constant eccentricity). The predictions of the proposed model for moment and deformation capacity are shown in tabulated form in Appendix 5 (Tables $4^{7,16-20}$ and $5^{7,19,21-35}$ using the failure criterion CSCT(mono) for monotonic tests and CSCT(cyc) for cyclic tests. In addition, the predictions of ACI 318-14 2 and the model of Broms ${ }^{5}$ are presented in the same tables. In the following, the performance of the proposed model to predict the moment strength and the deformation capacity of slab-column connections is discussed. The evaluation is presented for square isolated slab specimens without transverse reinforcement supported on square columns subjected to constant vertical load and quasi-static monotonic or 

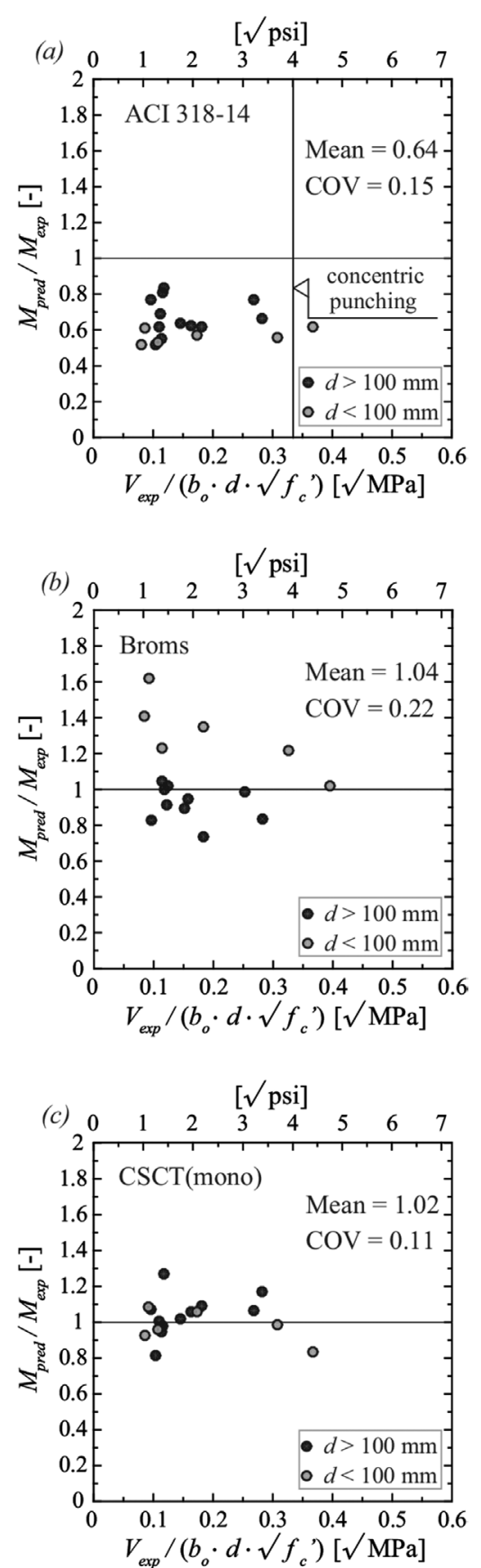

Fig. 8-Moment capacity predictions for specimens subjected to constant vertical load and monotonically increasing moment according to: (a) ACI 318-14²; (b) Broms $^{5}$; and (c) CSCT(mono).

cyclic moment. Tests on slabs subjected to constant eccentricity and monotonically increasing shear force (or equally moment) are not presented in the main part of the paper because the present study focuses on the seismic behavior of slab-column connections. Predictions for these tests can be found in Appendix 6 (Table 6). For all isolated specimens, the moment-rotation relationship was calculated assuming that each sector element extends until the inflection point under uniform vertical loading $\left(r_{s}=0.22 L\right)$. For tests using setup (c) (according to Fig. A6 in Appendix 3) where the vertical load was applied on the slab surface, the radius of the specimen is equal to $0.50 \mathrm{~L}$. For these cases (represented
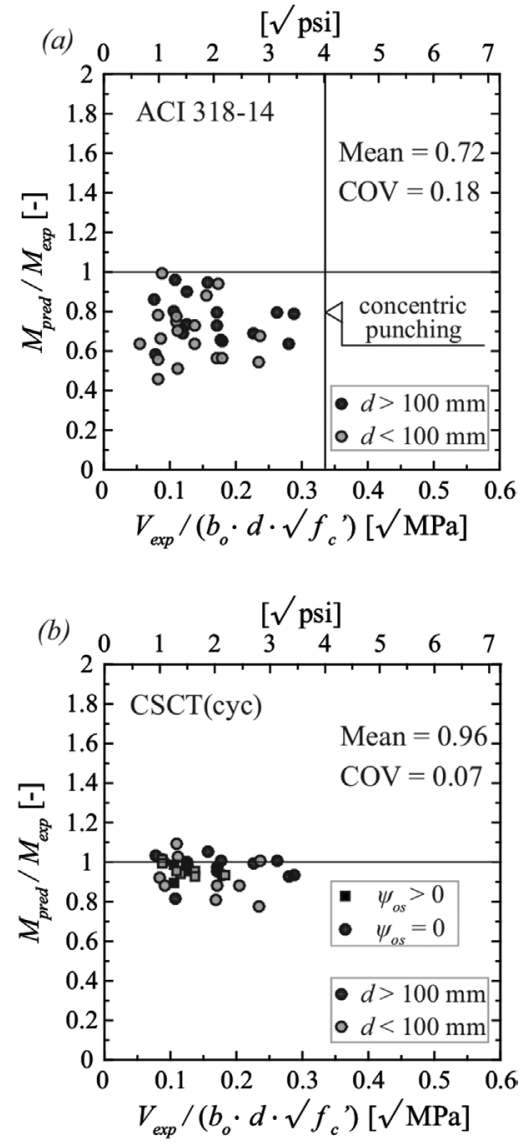

Fig. 9-Moment capacity predictions for specimens subjected to constant vertical load and cyclically increasing moment according to: (a) ACI 318-142; and (b) CSCT(cyc).

by square markers), the radial and tangential moments acting on the perimeter of the sector elements were not set to zero and effective beams were used to bridge the distance between $0.22 L$ and $0.50 L$ to account for the influence of the outer region of the slab on the moment-rotation response. For all other cases (represented by round markers), $0.22 \mathrm{~L}$ corresponds to the specimen radius and, therefore, the radial and tangential moments acting on the slab perimeter were set to zero.

\section{Moment capacity}

The moment capacity predicted by ACI $318-14,{ }^{2}$ Broms' model, ${ }^{5}$ and the proposed model are compared to the experimentally obtained moment capacities in Fig. 8 and 9. The abscissas of the graphs represent the normalized shear strength - that is, the shear force at failure divided by $b_{0} d \downarrow f_{c}$, where $d$ is the average effective slab depth, $f_{c}$ is the concrete compressive strength, and $b_{0}$ is the control perimeter located at $d / 2$ from the face of the column, calculated with rounded corners. ${ }^{36}$ Note that the normalized shear force $V / b_{0} d \downarrow f_{c}$ should be multiplied by 3 when using SI units and divided by 4 when using imperial units to obtain the Gravity Shear Ratio (GSR) defined according to ACI 318-14. ${ }^{2}$

Figure 8(a) shows the comparison for monotonic tests. On average, ACI $318-14^{2}$ yields rather conservative estimates of the moment capacity (ratio of predicted to observed values: $0.64 \pm 0.15$ ). Broms' model $^{5}$ shows better performance 

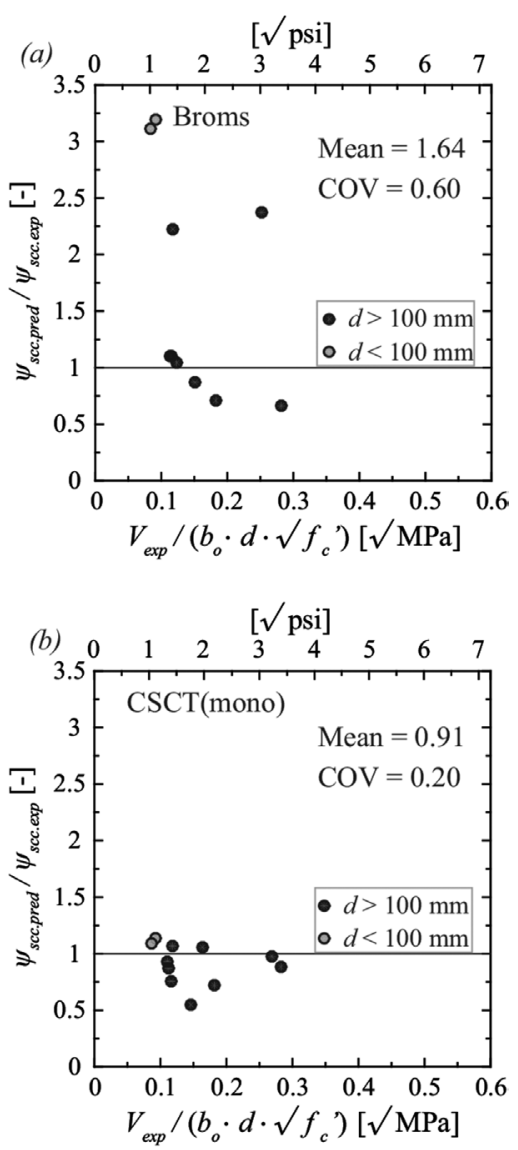

Fig. 10-Predictions of connection rotation at peak moment for specimens subjected to constant vertical load and monotonically increasing moment according to: (a) Broms ${ }^{5}$; and (b) $\operatorname{CSCT}$ (mono).

(Fig. 8(b)) with respect to the mean value of the ratio $M_{\text {pred }}$ $M_{\text {exp }}$ (1.04) but the results are largely scattered (COV = $22 \%$ ). The proposed model combined with the CSCT(mono) (Fig. 8(c)) yields higher prediction accuracy than Broms' model ${ }^{5}$ with respect to the average ratio of $M_{\text {pred }} / M_{\text {exp }}(1.02)$ and significantly reduced scatter $(\mathrm{COV}=11 \%)$.

The predictions of ACI $318-14^{2}$ for the moment strength of slabs subjected to cyclically increasing moment (Fig. 9(a)) display decreased conservatism compared to the predictions for slabs subjected to monotonically increasing moment (Fig. 8(a)) $(0.72 \pm 0.18)$. The proposed model combined with CSCT(cyc) (Fig. 9(b)) offers higher prediction accuracy with respect to both average ratio and scatter of predicted to observed moment capacities $M_{\text {pred }} / M_{\text {exp }}(0.96 \pm$ $0.07)$. Note that Broms' model is not applicable to cyclically loaded slabs. ${ }^{5}$

\section{Deformation capacity}

For seismic loading, the deformation capacity is as important as the moment capacity. Figures 10 and 11 present the predictions of ACI $318-14,{ }^{2}$ Broms' model,, 5 and the proposed model as ratio of calculated to measured rotation of the slab-column connection at peak moment. Although the conventional definition of the rotation capacity of structural members accounts for a reduction of $20 \%$ in strength, due to the brittle nature of the punching failure, this can be
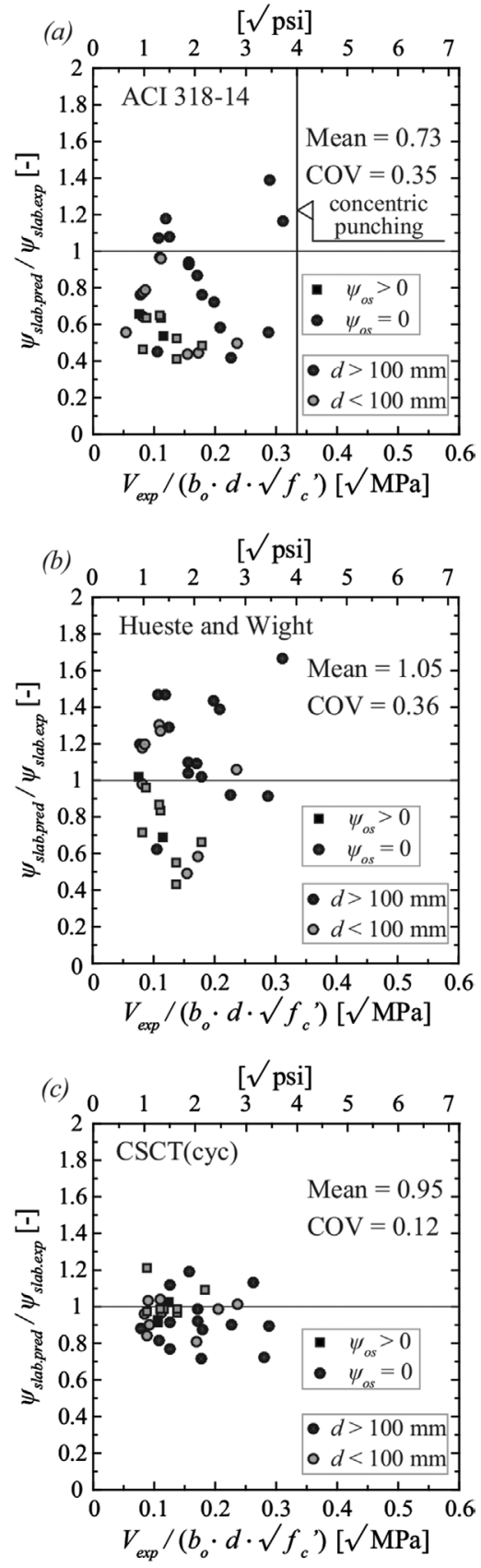

Fig. 11-Predictions of slab deformation at peak moment for specimens subjected to constant vertical load and cyclically increasing moment according to: (a) ACI 318-142; (b) Hueste and Wight ${ }^{4}$; and (c) CSCT(cyc).

approximated by the rotation at maximum strength. The tests were conducted under constant shear force and monotonically (Fig. 10) or cyclically (Fig. 11) increasing moment. Broms' model $^{5}$ is only compared to monotonic tests and ACI $318-14^{2}$ only to cyclic tests. Monotonic tests had all been performed on slab specimens of the size $0.44 \mathrm{~L} \times 0.44 \mathrm{~L}$. Cyclic tests had, however, partly been conducted on slab specimens of the size $1.0 \mathrm{~L} \times 1.0 \mathrm{~L}$. In this case, the total slab rotation $\psi_{\text {slab }}$ was computed using the Effective Beam Width Method described previously.

For monotonic tests, Broms' model ${ }^{5}$ (Fig. 10(a)) overestimates in average the rotation capacity and the prediction is also associated to a large scatter $(1.64 \pm 0.60)$. The proposed 

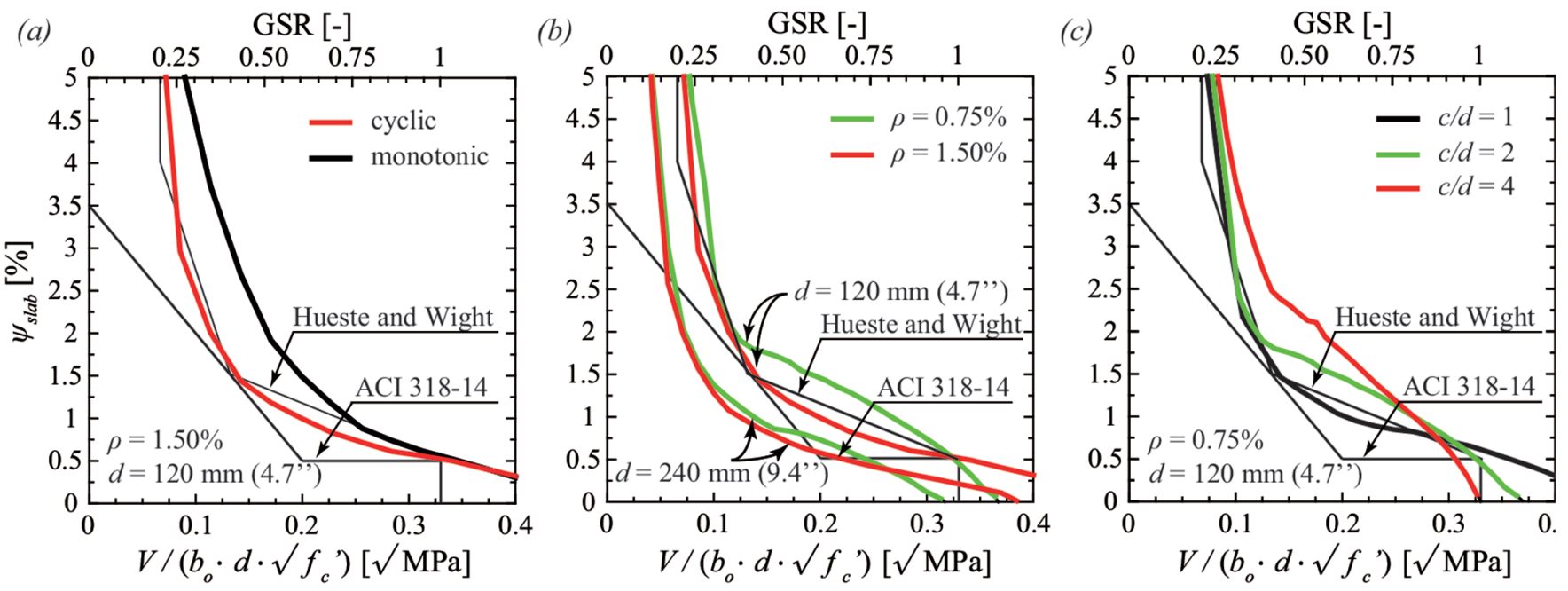

Fig. 12-Predicted slab rotation at peak moment and allowable drift limit according to ACI 318-142 and Hueste and Wight ${ }^{4}$ $\left(\mathrm{c}=2 \mathrm{~d} ; \mathrm{f}_{\mathrm{c}}=30 \mathrm{MPa}[4350 \mathrm{psi}] ;\right.$ and $\mathrm{f}_{\mathrm{y}}=460 \mathrm{MPa}$ [67 ksi]): (a) influence of loading conditions (cyclic versus monotonic) (L $=35 \mathrm{~d} ; \mathrm{d}_{\mathrm{g}}=16 \mathrm{~mm}[0.63 \mathrm{in.]}) ;($ b) influence of slab effective depth and reinforcement ratio on seismic rotation capacity $(\mathrm{L}=$ $35 \mathrm{~d} ; \mathrm{d}_{\mathrm{g}}=16 \mathrm{~mm}$ [0.63 in.]); and (c) influence of column size on seismic rotation capacity $\left(\mathrm{d}_{\mathrm{g}}=16 \mathrm{~mm}\right.$ [0.63 in.]).

model (CSCT(mono)) (Fig. 10(b)) provides conservative predictions and the scatter is reduced $(0.91 \pm 0.20)$ when compared to Broms' model. ${ }^{5}$

For the slab rotation of slabs subjected to constant shear force and cyclically increasing moment, ACI 318-142 (Fig. 11(a)) provides in average conservative predictions with rather high scatter $(0.73 \pm 0.35)$. The model proposed by Hueste and Wight ${ }^{4}$ (Fig. 11(b)) gives more precise average predictions but with similar scatter $(1.05 \pm 0.36)$. The $\mathrm{CSCT}(\mathrm{cyc})$ provides slightly conservative predictions and the scatter is reduced $(0.95 \pm 0.12)$ when compared to ACI $318-14^{2}$ and the model of Hueste and Wight ${ }^{4}$ (Fig. 11(c)).

\section{Seismic rotation capacity}

The proposed model is, in its current form, deformation-based and therefore integration in force-based design procedures is rather difficult. However, deformation-based models are steadily gaining significant popularity within the framework of performance-based seismic design that is of great importance for earthquake engineering. This section discusses the sensitivity of the rotation capacity of slabcolumn connections to several parameters. Figure 12 shows the predicted slab rotation $\psi_{\text {slab }}$ at peak moment according to the analytical model. The drift limit of ACI $318-14^{2}$ and the drift limit proposed by Hueste and Wight ${ }^{4}$ are also shown in the same graphs. All graphs of Fig. 12 show that the larger the gravity-induced shear, the smaller the rotation capacity of slab-column connections, as has been observed by others. ${ }^{3-}$ 5,37 The proposed model accounts for the effect of cyclic loading through the failure criterion (CSCT(cyc) against (CSCT(mono)). Figure 12(a) shows that the predicted deformation capacity under cyclic loading is between 5 and $45 \%$ smaller than for monotonic loading. The reduction in rotation capacity due to cyclic loading is more important for smaller gravity loads, confirming prior experimental observations. ${ }^{7}$

The model confirms Broms' observation that the rotation capacity decreases with increasing size of the slab
(Fig. 12(b)) with the slab span $L$ and the column size $c$ being increased proportionally to the effective depth $d$. Although the top reinforcement ratio significantly influences the local slab rotations, its effect on the rotation capacity of the slabcolumn connection is less pronounced (Fig. 12(b)). The column size has a significant effect on the rotation capacity. For the same gravity load, larger column size to effective depth ratio $c / d$ confers higher rotation capacity (Fig. 12(b)).

The drift limit of ACI $318-14^{2}$ for flat slabs represents a safe approach for a slab with $d=120 \mathrm{~mm}$ (4.7 in.). However, a slab with $d=240 \mathrm{~mm}$ (9.4 in.) does not reach the rotation capacity predicted by ACI $318-14^{2}$ for a gravity load ratio GSR $<0.55$ and $>0.7$ (Fig. 12(b)). For GSR $>0.7$, this observation is supported by experimental data (refer to Table 5). This is expected because the drift limit of ACI $318-14^{2}$ is based on experimental research on slabs with thickness $h \leq$ $152 \mathrm{~mm}(6$ in.).

If a minimum rotation capacity - for instance, $0.5 \%$ is required for the slab-column connection, the $120 \mathrm{~mm}$ (4.7 in.) slab meets this requirement for every gravity load value (as long as GSR < 1). For the $240 \mathrm{~mm}$ (9.4 in.) slab, the gravity load ratio GSR has to be limited to 0.7 to reach a drift of $0.5 \%$. If the building is designed for a drift value of $2.0 \%$ - a value that is often quoted as drift limit for RC wall buildings - the GSR must be smaller than 0.35 for slabs with $d=120 \mathrm{~mm}$ (4.7 in.), which is close to the value proposed by Hueste and Wight ${ }^{4}(\mathrm{GSR}<0.36)$. For slabs with $d=240 \mathrm{~mm}$ (9.4 in.), the GSR must be limited to 0.22 . This discussion accounted only for the contribution of the slab deformations to the interstory drift. The effective interstory drift capacity will be larger than the calculated slab rotation because the column deformation will also contribute to the interstory drift capacity (Eq. (1)).

\section{CONCLUSIONS}

This article presents a mechanical model for the moment-rotation relationship of slab-column connections without transverse reinforcement that are subjected to 
gravity loads and seismically induced lateral deformations. The model accounts explicitly for the three different loadtransfer actions between slab and column - that is, eccentric shear, flexure, and torsion. The failure criterion of the Critical Shear Crack Theory (CSCT) ${ }^{6}$ is adapted to predict the moment and rotation capacity of the slab-column connection. The effect of cyclic loading is considered by neglecting shear force redistribution between sector elements of the hogging slab half. The model was validated against 18 monotonic tests and 35 cyclic tests from 22 test campaigns reported in the literature. The comparison showed that the model predicts both moment and rotation capacity with a small bias and significantly smaller variability than existing analytical or empirical models. The model is used to investigate the sensitivity of the rotation capacity of slab-column connections to various parameters:

1. The model confirms that the rotation capacity of slab-column connections reduces with increasing gravity shear ratio.

2. The model also confirms the experimental finding that cyclic loading leads to smaller slab rotation capacities than monotonic loading. In addition, the smaller the gravity load, the larger the reduction in rotation capacity due to cyclic loading.

3. It is shown that an increase of the slab effective depth (slab span to effective depth ratio $L / d$ and column size to effective depth ratio $c / d$ maintained constant) leads to a significant reduction in rotation capacity (size effect on rotation capacity). For this reason, empirical models for the rotation capacity of slab-column connections should not be applied to larger slabs than those used for the calibration of the empirical model.

4. The column size has a significant effect on the rotation capacity. For the same GSR (gravity shear ratio), larger column size to effective depth ratio $c / d$ leads to a higher rotation capacity.

5. While the influence of the top reinforcement on the moment capacity is paramount, its influence on the rotation capacity of the slab-column connection is rather small.

\section{AUTHOR BIOS}

Ioannis-Sokratis Drakatos is a Structural Engineer and Researcher. He received his MS from the University of Patras, Patras, Greece, and his PhD from Ecole Polytechnique Fédérale de Lausanne (EPFL), Lausanne, Switzerland. His research interests include punching shear and behavior of reinforced concrete structures under seismic and blast loads.

Aurelio Muttoni is a Professor and Head of the Structural Concrete Laboratory at EPFL-ENAC. He received the ACI Chester Paul Siess Award for Excellence in Structural Research in 2010 and was a co-recipient of the ACI Wason Medal for the Most Meritorious Paper in 2014. His research interests include theoretical bases of the design of reinforced concrete structures, shear and punching shear, fiber-reinforced high-strength concrete, soil-structure interaction, and the conceptual design of bridges.

Katrin Beyer is an Associate Professor and Head of the Earthquake Engineering and Structural Dynamics Laboratory at EPFL. Her research interests include the seismic behavior of reinforced concrete walls and unreinforced masonry structures.

\section{ACKNOWLEDGMENTS}

The work presented in this article was funded by the Association of the Swiss Cement Industry (Grant No. 201201) and by the Swiss National Science Foundation (Grant No. 143747). The support offered to the authors is gratefully acknowledged.

\section{REFERENCES}

1. Mast, P. E., "Stresses in Flat Plates Near Columns," ACI Journal Proceedings, V. 67, No. 10, Oct. 1970, pp. 761-768.

2. ACI Committee 318, "ACI Building Code Requirements for Structural Concrete (ACI 318-14) and Commentary (ACI 318R-14)," American Concrete Institute, Farmington Hills, MI, 2014, 519 pp.

3. Pan, A., and Moehle, J. P., "Lateral Displacement Ductility of Reinforced Concrete Flat Plates," ACI Structural Journal, V. 86, No. 3, May-June 1989, pp. 250-258.

4. Hueste, M. B. D., and Wight, J. K., "Nonlinear Punching Shear Failure Model for Interior Slab-Column Connections," Journal of Structural Engineering, ASCE, V. 125, No. 9, 1999, pp. 997-1008. doi: 10.1061/ (ASCE)0733-9445(1999)125:9(997)

5. Broms, C. E., "Design Method for Imposed Rotations of Interior SlabColumn Connections," ACI Structural Journal, V. 106, No. 5, Sept.-Oct. 2009, pp. 636-645.

6. Muttoni, A., "Punching Shear Strength of Reinforced Concrete Slabs without Transverse Reinforcement," ACI Structural Journal, V. 105, No. 4, July-Aug. 2008, pp. 440-450.

7. Drakatos, I. S.; Beyer, K.; and Muttoni, A., "Internal Slab-Column Connections under Monotonic and Cyclic Imposed Rotations," Engineering Structures, V. 123, Sept. 2016, pp. 501-516. doi: 10.1016/j. engstruct.2016.05.038

8. CSI, "Structural Analysis Program (SAP2000) v17.0 (Trial)," Computers and Structures Inc., Berkeley, CA, 2007.

9. Kinnunen, S., and Nylander, H., "Punching of Concrete Slabs without Shear Reinforcement," Transactions of the Royal Institute of Technology, No. 158, Stockholm, Sweden, 1960, 112 pp.

10. Pan, A., and Moehle, J. P., "An Experimental Study of SlabColumn Connections," ACI Structural Journal, V. 86, No. 6, Nov.-Dec. 1992, pp. 626-638.

11. Park, H., and Choi, K., "Improved Strength Model for Interior Flat Plate-Column Connections Subject to Unbalanced Moment," Journal of Structural Engineering, ASCE, V. 132, No. 5, 2006, pp. 694-704. doi: 10.1061/(ASCE)0733-9445(2006)132:5(694)

12. Einpaul, J.; Ospina, C. E.; Fernández Ruiz, M.; and Muttoni, A., "Punching Shear Capacity of Continuous Slabs," ACI Structural Journal, V. 113, No. 4, July-Aug. 2016, pp. 861-872. doi: 10.14359/51688758

13. Einpaul, J.; Fernández Ruiz, M.; and Muttoni, A., "Influence of Moment Redistribution and Compressive Membrane Action on Punching Strength of Flat Slabs," Engineering Structures, V. 86, Mar. 2015, pp. 43-57. doi: 10.1016/j.engstruct.2014.12.032

14. Rha, C.; Kang, T. H.-K.; Shin, M.; and Yoon, J. B., "Gravity and Lateral Load-Carrying Capacities of Reinforced Concrete Flat Plate Systems," ACI Structural Journal, V. 111, No. 4, July-Aug. 2014, pp. 753-764. doi: $10.14359 / 51686731$

15. Sagaseta, J.; Muttoni, A.; Fernández Ruiz, M.; and Tassinari, L., "Non-Axis-Symmetrical Punching Shear around Internal Columns of RC Slabs without Transverse Reinforcement," Magazine of Concrete Research, V. 63, No. 6, 2011, pp. 441-457. doi: 10.1680/macr.10.00098

16. Ghali, A.; Sargious, M.A.; and Huizer, A., "Vertical Prestressing of Flat Plates around Columns," Shear Transfer of Reinforced Concrete Beams under Reversed Loading, SP-42, V. 2, R. H. Brown and J. O. Jirsa, eds., American Concrete Institute, Farmington Hills, MI, 1974, pp. 905-920.

17. Stamenkovic, A., and Chapman, J. C., "Local Strength at Column Heads in Flat Slabs Subjected to a Combined Vertical and Horizontal Loading," Institution of Civil Engineers Proceedings, V. 57, No. 2, 1974, pp. 205-232. doi: 10.1680/iicep.1974.4054

18. Ghali, A.; Elmasri, M.; and Dilger, W., "Punching of Flat Plates under Static and Dynamic Horizontal Forces," ACI Journal Proceedings, V. 73, No. 10, Oct. 1976, pp. 566-572.

19. Islam, S., and Park, R., "Tests on Slab-Column Connections with Shear and Unbalanced Flexure," Journal of the Structural Division, ASCE, V. 102, Mar. 1976, pp. 549-568.

20. Elgabry, A., and Ghali, A., "Tests on Concrete Slab-Column Connections with Stud-Shear Reinforcement Subjected to Shear-Moment Transfer," ACI Structural Journal, V. 84, No. 5, Sept.-Oct. 1987, pp. 433-442.

21. Kanoh, Y., and Yoshizaki, S., "Experiments on Slab-Column and Slab-Wall Connections of Flat Plate Structures," Concrete Journal, V. 13, June 1975, pp. 7-19. (Tokyo)

22. Morrison, D. G.; Hirasawa, I.; and Sozen, M. A., "Lateral-Load Tests of RC Slab-Column Connections," Journal of Structural Engineering, ASCE, V. 109, No. 11, 1983, pp. 2698-2714. doi: 10.1061/ (ASCE)0733-9445(1983)109:11(2698)

23. Zee, H. L., and Moehle, J. P., "Behavior of Interior and Exterior Flat Plate Connections Subjected to Inelastic Load Reversals," Report UCB/EERC 84/07, Earthquake Engineering Research Center, College of 
Engineering, University of California, Berkeley, Berkeley, CA, Aug. 1984, $145 \mathrm{pp}$.

24. Cao, H., "Seismic Design of Slab-Column Connections," master's thesis, University of Calgary, Calgary, AB, Canada, 1993, 201 pp.

25. Robertson, I. N.; Kawai, T.; Lee, J.; and Enomoto, B., "Cyclic Testing of Slab-Column Connections with Shear Reinforcement," ACI Structural Journal, V. 99, No. 5, Sept.-Oct. 2002, pp. 605-613.

26. Stark, A.; Binici, B.; and Bayrak, O., "Seismic Upgrade of Reinforced Concrete Slab-Column Connections Using Carbon Fiber-Reinforced Polymers," ACI Structural Journal, V. 102, No. 2, Mar.-Apr. 2005, pp. 324-333.

27. Robertson, I. N., and Johnson, G., "Cyclic Lateral Loading of Nonductile Slab-Column Connections," ACI Structural Journal, V. 103, No. 3, May-June 2006, pp. 356-364.

28. Choi, M.-S.; Cho, I.-J.; Han, B.-S.; Ahn, J.-M.; and Shin, S.-W., "Experimental Study of Interior Slab-Column Connections Subjected to Vertical Shear and Cyclic Moment Transfer," Key Engineering Materials, V. 348-349, Sept. 2007, pp. 641-644. doi: 10.4028/www.scientific.net/ KEM.348-349.641

29. Park, Y.-M.; Han, S.-W.; and Ryu, J.-H., "Comparison of Seismic Behaviors of Interior Joints in PT and RC Flat Plate Systems," Key Engineering Materials, V. 348-349, Sept, 2007, pp. 741-745.

30. Kang, T. H.-K., and Wallace, J. W., "Seismic Performance of Reinforced Concrete Slab-Column Connections with Thin Plate Stirrups," ACI Structural Journal, V. 105, No. 5, Sept.-Oct. 2008, pp. 617-625.
31. Tian, Y.; Jirsa, J. O.; Bayrak, O., Widianto; and Argudo, J. F., "Behavior of Slab-Column Connections of Existing Flat-Plate Structures," ACI Structural Journal, V. 105, No. 5, Sept.-Oct. 2008, pp. 561-569.

32. Bu, W., and Polak, M. A., "Seismic Retrofit of Reinforced Concrete Slab-Column Connections Using Shear Bolts," ACI Structural Journal, V. 106, No. 4, July-Aug. 2009, pp. 514-522.

33. Cho, Y. S., "Structural Performance of RC Flat Plate Slab Shear-Reinforced Interior Connections under Lateral Loading," Magazine of Concrete Research, V. 61, No. 3, 2009, pp. 155-164. doi: 10.1680/macr.2007.00059

34. Choi, J.-W.; Ali, M.; and Alexander, S. D. B., "Behavior of SlabColumn Connections with Partially Debonded Reinforcement under Lateral Loading," Canadian Journal of Civil Engineering, V. 36, No. 3, 2009, pp. 463-472. doi: 10.1139/L09-006

35. Park, H.-G.; Kim, Y.-N.; Song, J.-G.; and Kang, S.-M., "Lattice Shear Reinforcement for Enhancement of Slab-Column Connections," Journal of Structural Engineering, ASCE, V. 138, No. 3, 2012, pp. 425-437. doi: 10.1061/(ASCE)ST.1943-541X.0000484

36. Fédération international du béton, " $f i b$ Model Code for Concrete Structures 2010," Ernst \& Sohn, Berlin, Germany, 2013, 434 p.

37. Choi, K.-K.; Shin, D.-W.; and Park, H.-G., "Shear-Strength Model for Slab-Column Connections Subjected to Unbalanced Moment," ACI Structural Journal, V. 111, No. 3, May-June 2014, pp. 491-502. doi: $10.14359 / 51686533$ 


\section{APPENDIX 1}

\section{ACI-318 provisions for moment transfer in slab-column connections}

3 Itis assumed that a fraction of the unbalanced moment (equal to the coefficient $\gamma_{v}$ ) is resisted

4 by the eccentric shear force mechanism. The shear stresses due to the unbalanced moment $M$

5 are superimposed to the shear stresses due to vertical loads $V$ :

$$
v_{E}=\frac{V}{b_{0, A C I} \cdot d} \pm \frac{\gamma_{v} \cdot M \cdot j_{d}}{J_{c}}
$$

8 where $b_{0, A C I}$ is the length of the control perimeter (located at a distance of $d / 2$ from the column

9 face), $j_{d}$ is the distance between the centroid and edge of the critical perimeter, and $J_{c}$ is the 10 polar moment of inertia of the critical perimeter.

11 The total maximum shear stress $v_{R}$ acting on the control perimeter is:

$$
v_{R}=\min \left\{0.17 \cdot\left(1+\frac{2}{\beta_{c}}\right), 0.083 \cdot\left(2+\frac{\alpha_{s} \cdot d}{b_{0, A C I}}\right), \frac{1}{3}\right\} \cdot \sqrt{f_{c}}
$$

14 where $\beta_{c}$ is the ratio of long to short side of the column and $\alpha_{s}$ is a parameter equal for 40 for

15 interior slab-column connections, 30 for exterior slab-column connections, and 20 for corner

16 slab-column connections. The slabs tested in this program are controlled by the third term of

17 Eq. A.2.

18 According to ACI-318 the unbalanced moment cannot be larger than the moment resisted by

19 flexure by the hogging and sagging reinforcement $\left(m_{R, h o g}\right.$ and $m_{R, s a g}$, respectively) over a width equal to $c+3 h$. The maximum unbalanced moment can therefore be calculated using the

21 following formula: 


$$
M_{\max }=\min \left\{\frac{v_{R^{-}} \frac{V}{b_{0, A C I} d}}{\gamma_{v} j_{d}} \cdot J_{c}, \frac{\left(m_{R, h o g}+m_{R, s a g}\right) \cdot(c+3 \cdot h)}{1-\gamma_{v}}\right\}
$$

1

2

3 column connections. Based on the study by Pan and Moehle ${ }^{\text {Error! Reference source not found. the }}$

4 maximum admissible drift (in rad) is a function of the applied shear force on the slab-column

5 connection:

6

$$
\psi_{s t, u}=\max \left\{0.005,0.035-0.05 \cdot \frac{V}{V_{R}}\right\}
$$

\section{7}

8 where $V_{R}$ is the punching strength of the slab-column connection according to Eq. A.2.

\section{$11 \quad$ Numerical analyses}

12 To simulate the behavior of an internal slab-column connection, an element $L \times L$ with

13 continuity boundary conditions (Fig. A1(a)) was analyzed using the finite element program

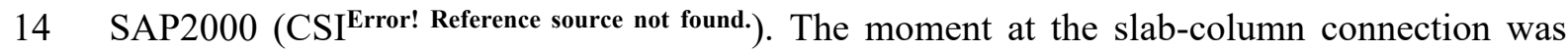

15 inserted through incrementally increasing lateral loads at the top of the column stub while

16 monitoring the rotation at the slab-column node. A uniform gravity pressure $q_{V}$ was applied at

17 the slab surface to simulate the vertical loads. The slab was modeled using nonlinear layered

18 shell elements with a Mindlin-Reissner formulation to include transverse shear deformations.

19 Only elastic shear deformations were included; the model could therefore only predict the

20 nonlinear flexural response. Fourteen integration points were used over the height of the slab.

21 The unconfined concrete model by Mander et al. ${ }^{38}$ and the model by Park and Paulay ${ }^{39}$ were

22 used for modeling the nonlinear behavior of concrete and reinforcing steel, respectively. 
1 Perfect bond between concrete and reinforcing bars was assumed. The tensile strength of the

2 concrete was assumed to be zero since using a non-zero stress-strain law for tension resulted

3 in considerable convergence issues in SAP2000. The column member was modeled as rigid

4 and was pinned at the base $\left(\delta_{x, y, z}=0\right)$ and free at the top. The slab edges parallel to the $x$ axis

5 were restrained against rotation about the same axis $\left(\theta_{x}=0\right)$ whereas the other edges were

6 constrained to have the same vertical displacement $\left(\delta_{z}\right)$ and rotation about the $y$ axis $\left(\theta_{y}\right)$ as

7 shown in Figure A1(a). Since the column is rigid ( $\psi_{c o l}=0$, Fig. A1(a)), the slab rotation $\left(\psi_{r<0.22 L}\right.$

$\left.8+\psi_{r}>0.22 L\right)$ is equal to the interstory drift $\psi_{s t}$.

9 For the analyzed example, the column size $c$ was $390 \mathrm{~mm}[15.4$ ' '], the slab thickness $h$ was

$10250 \mathrm{~mm}\left[9.8^{\prime \prime}\right]$ and the specimen size $L$ was $6.8 \mathrm{~m}$ [22' 4' $]$. The reinforcement ratio activated

11 by lateral forces in each direction was equal to $0.75 \%$ in the zone of the slab near the column

12 (1.5 $\mathrm{m}$ from the column's center) and $0.5 \%$ in the middle strip. Bottom reinforcement was

13 provided in both directions around the column, with a ratio equal to $50 \%$ of the top

14 reinforcement ratio. The quasi-permanent vertical loads consisted of $6.25 \mathrm{kN} / \mathrm{m}^{2}$ [130.6 psf] of

15 self-weight of the slab, $1.00 \mathrm{kN} / \mathrm{m}^{2}$ [20.9 psf] superimposed load and $0.60 \mathrm{kN} / \mathrm{m}^{2}$ [12.5 psf]

16 quasi-permanent live load. Under this load combination, the vertical load acting on an interior

17 slab-column connection was approximately $40 \%$ of the punching strength according to

18 ACI318-14 Error! Reference source not found, using mean strength values. The assumed concrete

19 compressive strength was $32 \mathrm{MPa}$ [4641 psi] and the yield and maximum tensile stress of the

20 reinforcing steel were $550 \mathrm{MPa}[79.8 \mathrm{ksi}]$ and $680 \mathrm{MPa}$ [98.6 ksi], respectively.

21 Figure A1(b) shows the established effective beam width model to calculate the contribution

22 of the slab region outside $0.22 L$ to the slab deformation rotation $\psi_{\text {slab. }}$. The only differences

23 between the models shown in Figure A1(a) and (b) lie on the use of beam members instead of

24 shell elements, distribution of the gravity loads per unit length instead of unit area and modeling

25 of the beam part inside $0.22 L$ with high stiffness. 

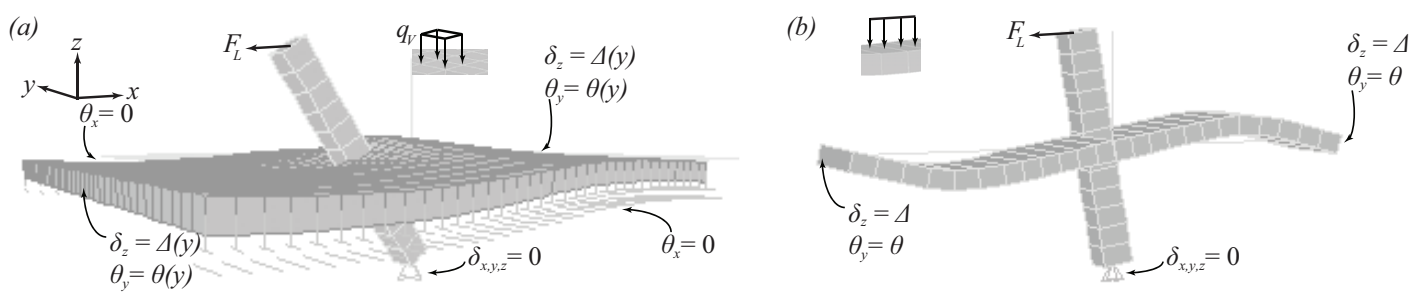

Fig. A1-Deformed shape of (a) slab element $L x L$ with continuity boundary conditions and (b) effective beam width model with high stiffness for $r<0.22 L$.

1

2

3 7

\section{References}

38. Mander, J.B.; Priestley, M.J.N.; and Park, R, "Theoretical stress-strain model for confined concrete," Journal Structural Engineering, ASCE, V. 114, No. 8, Aug. 1988, pp. 1804-1826.

39. Park, R., and Paulay, T., "Reinforced Concrete Structures," John Wiley, New York, 1975.

\section{APPENDIX 3}

\section{Test setups for experimental investigation of flat slabs under seismically-induced} deformations

12 For tests on a single interior slab-column connection different test setups were developed concerning the slab and column boundary conditions as well as the way lateral loads were simulated. However, all test setups can be assigned to one of the following three schemes (Fig. $A 2)$ :

- Test setup (a): the unbalanced moment is introduced by an eccentric vertical load and by restraining the vertical displacement of the slab ends (Fig. A2). 


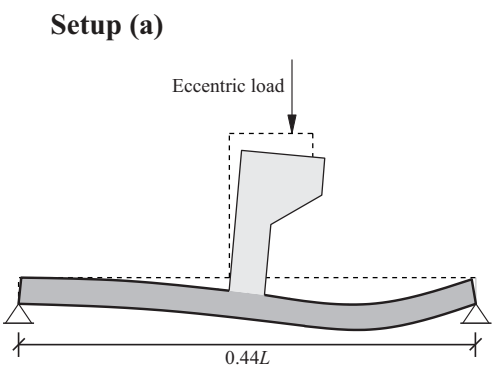
ends (Fig. A2 and A3).

- Test setup (b): the unbalanced moment is introduced by applying unequal vertical loads to the ends of the slab and by restraining the horizontal displacement of the column stub

- Test setup (c): the unbalanced moment is introduced by applying a horizontal force to the top column stub and by restraining the vertical displacement of the slab edges (Fig. A2 and A3). The vertical load is applied either by jacks underneath the column stub (monotonic tests - Fig. A2) or by weights on the slab surface (cyclic tests - Fig. A3).

The setup configuration adopted in each test campaign is indicated in column 1 of Tables 1 and 2 (Appendix 4), after the year of publication of the associated article.

......- Undeformed shape
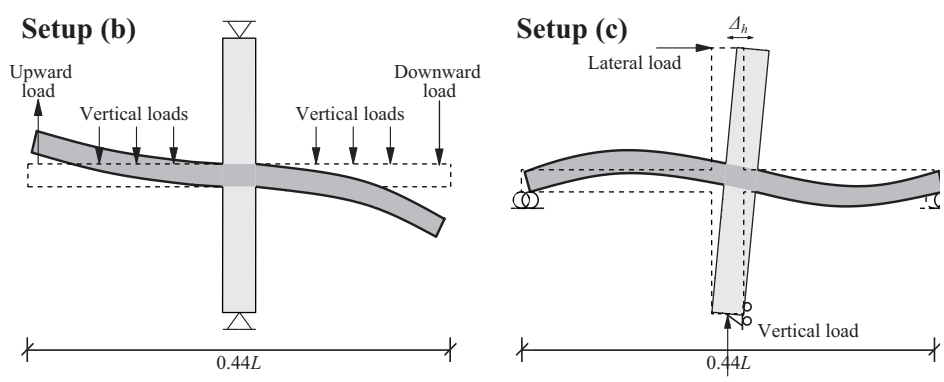

Fig. A2 - Test setup configurations used in previous experimental campaigns for slabcolumn connections with monotonic moment transfer (Drakatos et al. Error! Reference source not found.).

10
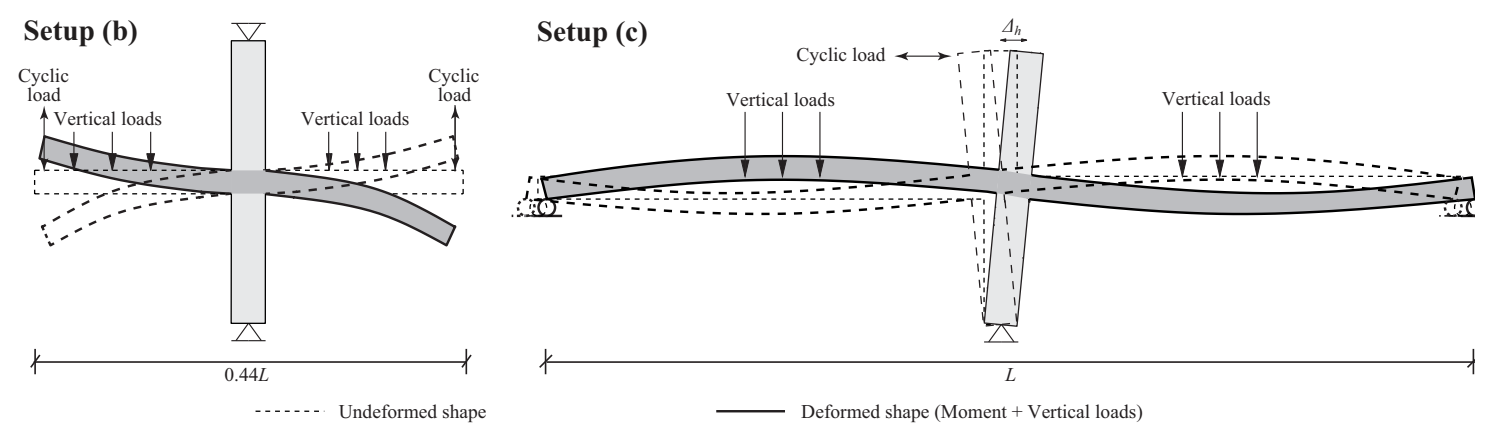

Fig. A3 - Test setup configurations used in previous experimental campaigns for slabcolumn connections with cyclic moment transfer. 
2 In the following, the definition of the slab-column connection rotation for the setups that are

3 most suitable for simulating seismically-induced deformations (setups (b) and (c)) is briefly

4 discussed. The deformed shape of the slab for each setup is also shown in the following

5 sections. The adopted numerical method is presented in Appendix 2.

6

\section{$7 \quad$ Setup (b)}

8 For setup (b), the deformed shape of the slab under vertical loads, lateral loads and combined

9 vertical and lateral loads is shown in Figure A4. The deformed shape assumed by the proposed

10 model is also shown in the same figure.

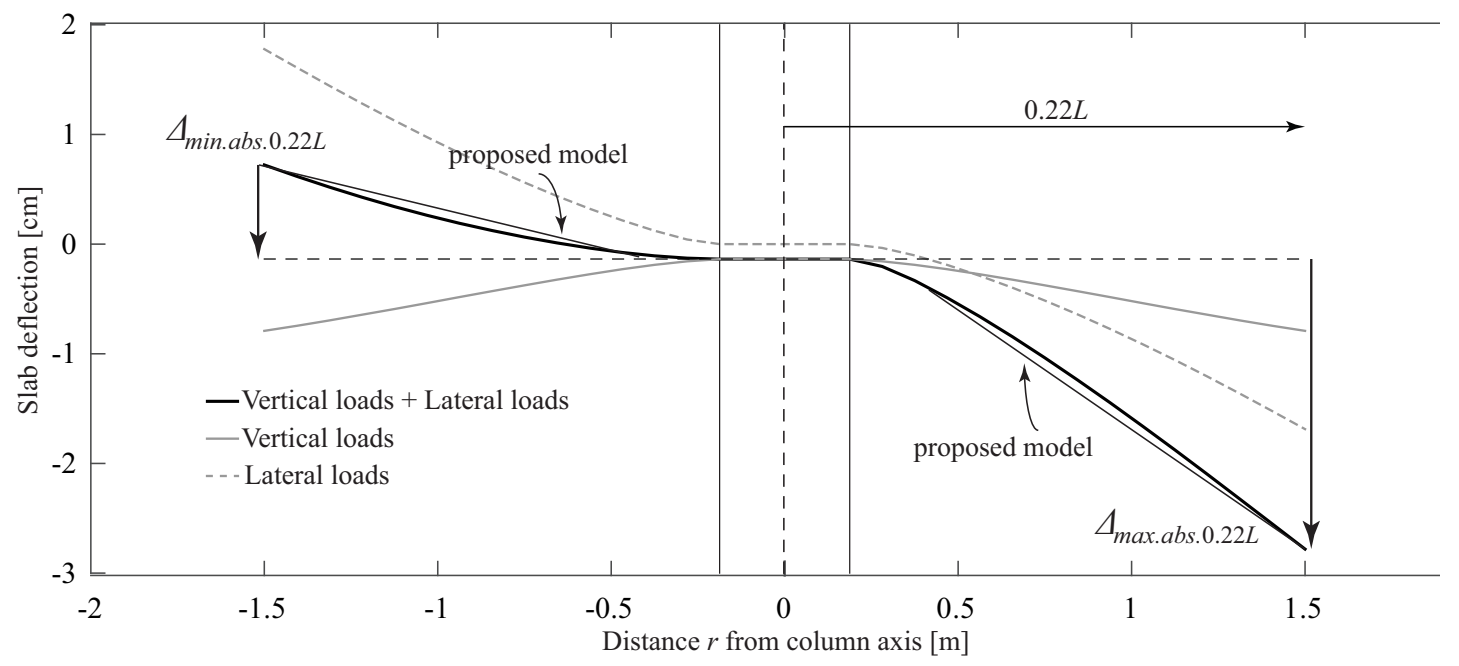

Fig. A4 - Setup (b): Deformed shape of slab according to finite element analysis and the proposed model.

11

12 Therefore, for this setup configuration the slab-column connection rotation can be calculated

13 either based on rotations:

$$
\psi_{\text {scc.rot }}=\frac{\psi_{\max }-\psi_{\min }}{2}=\frac{\Delta_{\max }-\Delta_{\min }}{2 \cdot \Delta r}
$$

14 or on deflections: 


$$
\psi_{\text {scc.defl }}=\frac{\Delta_{\max }-\Delta_{\min }}{2 \cdot \Delta r+c}
$$

1 Finite element analyses have shown that, for this setup configuration, calculation of the slab-

2 column connection rotation on the basis of deflections provides more realistic estimation of the

3 interstory drift of an internal connection of the reference slab-column frame (Drakatos et

4 al. Error! Reference source not found.). This definition was therefore used both for the experimental peak

5 connection rotations (Appendix 4) and the predicted peak connection rotations (Appendix 5)

6 for the slabs tested using this setup.

\section{$8 \quad$ Setup (c)}

9 For setup (c) the deformed shape of the slab depends on the way the vertical loads are applied:

10 For vertical loads applied by jacks underneath the column stub (Fig. A5) the deformed shape

11 resembles the deformed shape for setup (b) (Fig. A4); for vertical loads applied on the slab

12 surface (Fig. A5) the deformed shape is significantly different since the slab region between $r$

$13=0.22 L$ and $0.50 L$ contributes to the slab deformation.

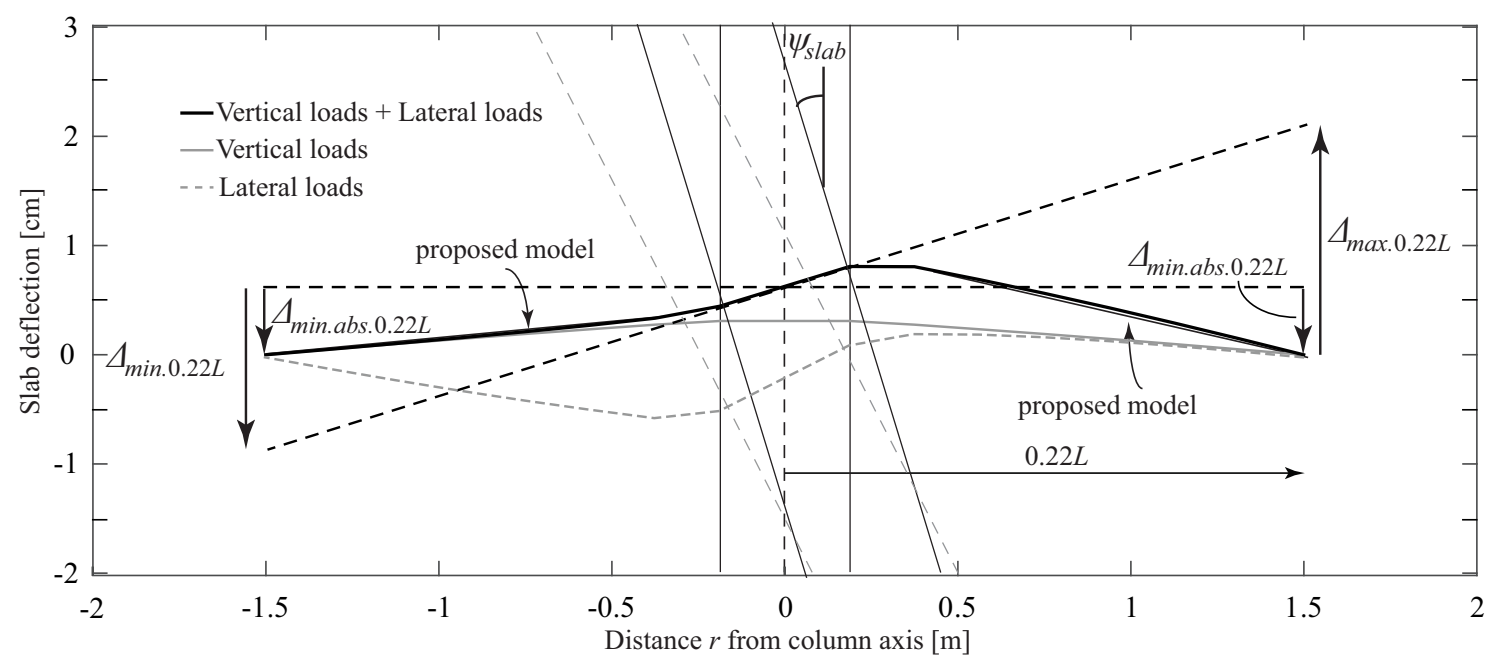

Fig. A5 - Setup (c) with vertical load applied on the column: Deformed shape of slab according to finite element analysis and the proposed model. 
1 According to the proposed model the slab-column connection rotation based on rotations is:

$$
\psi_{\text {scc.rot }}=\frac{\psi_{\max }-\psi_{\min }}{2}=\frac{\left(\Delta_{\text {max.abs }}+\psi_{s c c} \cdot \Delta r\right)}{2 \cdot \Delta r}-\frac{\left(\Delta_{\text {min.abs }}-\psi_{s c c} \cdot \Delta r\right)}{2 \cdot \Delta r}=\frac{\left(\Delta_{\text {max. } a b s}-\Delta_{\text {min.abs }}\right)}{2 \cdot \Delta r}+\psi_{s c c}
$$

2 The connection rotation based on deflections is:

$$
\psi_{\text {scc.defl }}=\frac{\Delta_{\max }-\Delta_{\min }}{2 \cdot \Delta r+c}=\frac{\left(\Delta_{\text {max.abs }}+\psi_{s c c} \cdot \Delta r\right)}{2 \cdot \Delta r+c}-\frac{\left(\Delta_{\text {min.abs }}-\psi_{s c c} \cdot \Delta r\right)}{2 \cdot \Delta r+c}=\psi_{s c c} \cdot \frac{\Delta r}{2 \cdot \Delta r+c}
$$

3 For setup (c) with the vertical load applied on the column, since the deflections of the tip of

4 the hogging and sagging slab half relative to the column center ( $\Delta_{\max }$ abs and $\Delta_{\text {min.abs }}$

5 respectively) are equal (Fig. A6), the connection rotation that is calculated according to the

6 proposed model based on rotations is equal to the interstory drift (with zero rotation due to

7 column deformation). Therefore, this last definition of connection rotation $-\left(\psi_{\text {scc.rot }}-\right.$ Eq.

8 (Error! Reference source not found.)) will be used for the comparison of the proposed model

9 with experimentally measured interstory drift for tests using setup (c) (Appendix 5).

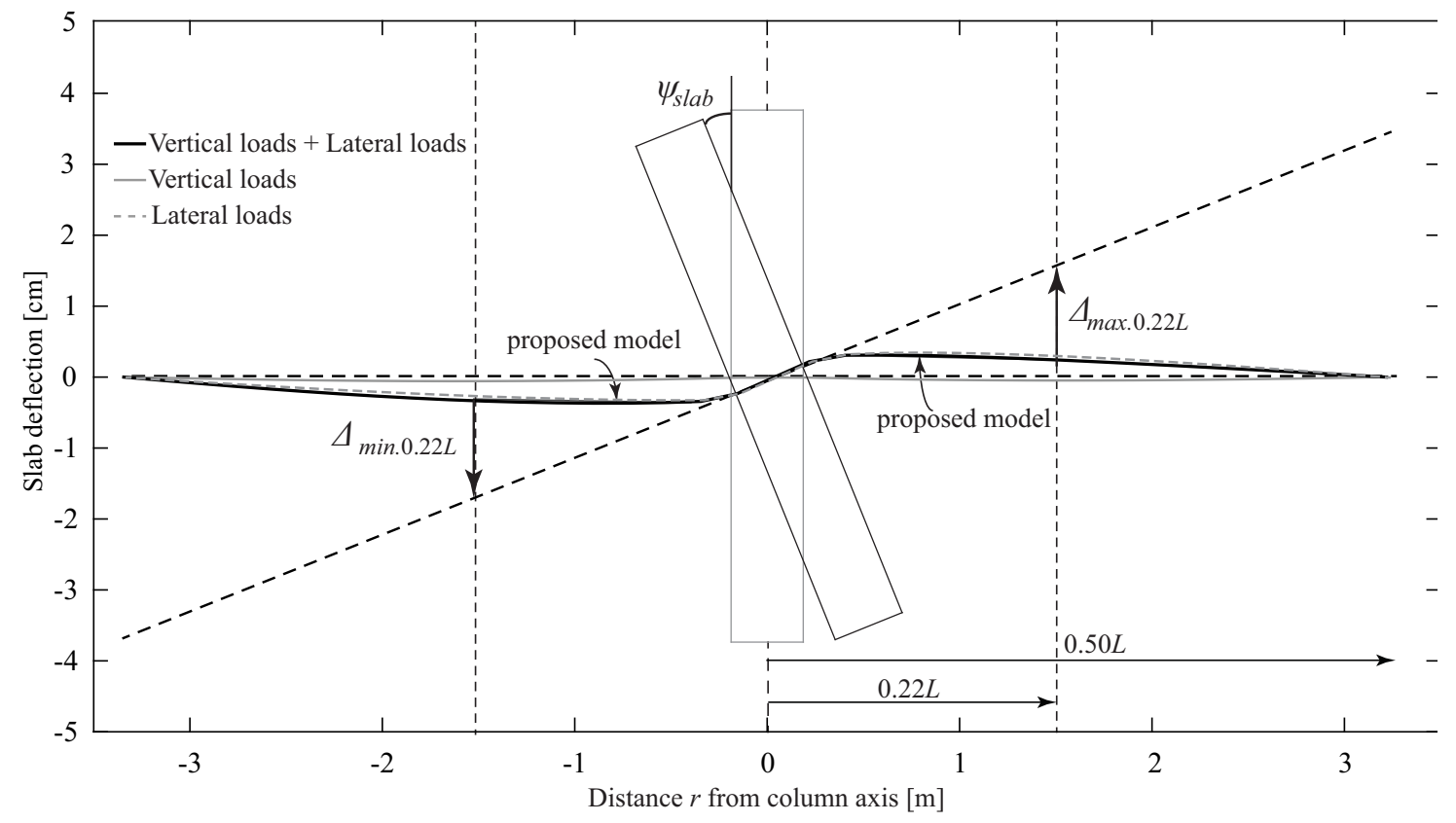

Fig. A6 - Setup (c) with vertical load applied on the slab surface: Deformed shape of slab according to finite element analysis and the proposed model. 
1 For setup (c) with the vertical load applied on the slab surface, since the slab part between

$20.22 L$ and $0.50 L$ contributes to the rotation due to slab deformation $\psi_{\text {slab }}$, the connection

3 rotation that is calculated according to the proposed model is smaller than the interstory drift

4 (with zero rotation due to column deformation). For this case, an effective beam model should

5 be established in order to calculate the contribution of the slab part outside $0.22 L$ to the 6 interstory drift.

7 It should be mentioned that for the experimental investigation using the setups that are the 8 most suitable for simulating seismically-induced deformations (setups (b) and (c)) a 9 contribution of column deformation to the interstory drift could occur. However, for setup (b)

10 the column was most times post-tensioned to reduce column deformation (Drakatos et al. ${ }^{\text {Error! }}$

11 Reference source not found.) and for setup (c) the column was typically designed to remain elastic

12 during the moment introduction. Nevertheless for both setups the contribution of column 13 deformation was measured by most researchers and subtracted from the measured connection 14 rotation. 
APPENDIX 4

2 Table 1-Summary of properties and results of interior slab-column specimens tested 3 under constant vertical load and monotonically increasing moment

\begin{tabular}{|c|c|c|c|c|c|c|c|c|c|c|c|c|}
\hline \multirow[t]{2}{*}{ Source } & \multirow[t]{2}{*}{ Mark } & \multicolumn{3}{|c|}{$\begin{array}{l}\text { Geometric } \\
\text { properties }\end{array}$} & \multicolumn{5}{|c|}{$\begin{array}{l}\text { Material properties and } \\
\text { reinforcement }\end{array}$} & $\begin{array}{c}\text { Loading } \\
\text { parameter }\end{array}$ & \multicolumn{2}{|c|}{ Results } \\
\hline & & $\begin{array}{c}c, \\
\mathrm{~mm}\end{array}$ & $\begin{array}{c}d, \\
\mathrm{~mm}\end{array}$ & $\begin{array}{l}B, \\
\mathrm{~m}\end{array}$ & $\begin{array}{c}f_{c}, \\
\mathrm{MPa}\end{array}$ & $\begin{array}{c}d_{g}, \\
\mathrm{~mm}\end{array}$ & $\begin{array}{c}f_{y}, \\
\mathrm{MPa}\end{array}$ & $\begin{array}{l}\rho, \\
\%\end{array}$ & $\begin{array}{l}\rho \\
\% \\
\%\end{array}$ & $\begin{array}{c}V_{\text {test }} / b_{0} \cdot d \cdot \sqrt{f_{c^{\prime}}} \\
\sqrt{\mathrm{MPa}}\end{array}$ & $\begin{array}{l}M_{\text {exp }} \\
\mathrm{kNm}\end{array}$ & $\begin{array}{c}\psi_{s c c} \\
\%\end{array}$ \\
\hline \multirow[b]{2}{*}{$\begin{array}{l}\text { Ghali et } \\
\text { al.Error! } \\
\text { Reference } \\
\text { source not } \\
\text { found. (1974)- } \\
\text { (c) }\end{array}$} & B3NP & 305 & 114 & 1.81 & 23.7 & 16.0 & 345 & 1.39 & 1.39 & 0.114 & 162.0 & - \\
\hline & B5NP & 305 & 114 & 1.81 & 28.3 & 16.0 & 345 & 1.39 & 1.39 & 0.104 & 196.0 & - \\
\hline \multirow{4}{*}{$\begin{array}{l}\text { Stamenkovic } \\
\text { and } \\
\text { ChapmanError! } \\
\text { Reference } \\
\text { source not } \\
\text { found. (1974) - } \\
\text { (c) }\end{array}$} & $\mathrm{C} / \mathrm{I} / 1$ & 127 & 56 & 0.87 & 36.0 & 9.5 & 434 & 1.17 & 1.17 & 0.376 & 7.3 & - \\
\hline & $\mathrm{C} / \mathrm{I} / 2$ & 127 & 56 & 0.87 & 29.7 & 9.5 & 434 & 1.17 & 1.17 & 0.308 & 10.5 & - \\
\hline & $\mathrm{C} / \mathrm{I} / 3$ & 127 & 56 & 0.87 & 25.9 & 9.5 & 434 & 1.17 & 1.17 & 0.174 & 13.6 & - \\
\hline & $\mathrm{C} / \mathrm{I} / 4$ & 127 & 56 & 0.87 & 25.4 & 9.5 & 434 & 1.17 & 1.17 & 0.108 & 16.7 & - \\
\hline \multirow{3}{*}{$\begin{array}{l}\text { Ghali et } \\
\text { al.Error! } \\
\text { Reference } \\
\text { source not } \\
\text { found. (1976)- } \\
\text { (c) }\end{array}$} & SM0.5 & 305 & 120 & 1.83 & 36.8 & 16.0 & 476 & 0.47 & 0.18 & 0.111 & 100.0 & 3.60 \\
\hline & SM1.0 & 305 & 120 & 1.83 & 33.4 & 16.0 & 476 & 1.05 & 0.33 & 0.116 & 126.0 & 2.63 \\
\hline & SM1.5 & 305 & 120 & 1.83 & 39.9 & 16.0 & 476 & 1.35 & 0.39 & 0.107 & 132.0 & 2.10 \\
\hline Islam and & IP1 & 229 & 70 & 2.24 & 27.3 & 6.0 & 356 & 0.83 & 0.43 & 0.092 & 30.5 & 3.62 \\
\hline $\begin{array}{l}\text { ParkError! } \\
\text { Reference } \\
\text { source not } \\
\text { found. (1976)- } \\
\text { (b) }\end{array}$ & IP2 & 229 & 70 & 2.24 & 31.9 & 6.0 & 374 & 0.83 & 0.43 & 0.085 & 37.7 & 3.97 \\
\hline $\begin{array}{l}\text { Elgabry and } \\
\text { GhaliError! } \\
\text { Reference } \\
\text { source not } \\
\text { found. (1987)- } \\
\text { (c) }\end{array}$ & 1 & 250 & 123 & 1.80 & 35.0 & 16.0 & 452 & 1.30 & 0.43 & 0.149 & 130.0 & $1.66 \neq$ \\
\hline \multirow{3}{*}{$\begin{array}{l}\text { Drakatos et } \\
\text { al. Error! Reference } \\
\text { source not found. }\end{array}$} & PD1 & 390 & 204 & 3.00 & 37.9 & 16.0 & 559 & 0.79 & 0.38 & 0.091 & 526.0 & $1.66^{*}$ \\
\hline & PD3 & 390 & 198 & 3.00 & 34.9 & 16.0 & 558 & 0.81 & 0.38 & 0.281 & 200.0 & 0.45 \\
\hline & PD4 & 390 & 201 & 3.00 & 39.0 & 16.0 & 507 & 0.80 & 0.38 & 0.136 & 527.0 & 2.01 \\
\hline \multirow{3}{*}{$(2016)-(b)$} & PD5 & 390 & 198 & 3.00 & 37.5 & 16.0 & 507 & 0.81 & 0.38 & 0.181 & 461.0 & 2.19 \\
\hline & PD10 & 390 & 197 & 3.00 & 32.3 & 16.0 & 593 & 1.62 & 0.76 & 0.307 & 290.0 & 0.49 \\
\hline & PD12 & 390 & 194 & 3.00 & 35.5 & 16.0 & 546 & 1.62 & 0.76 & 0.176 & 469.0 & 1.21 \\
\hline
\end{tabular}

$\neq \psi_{\text {max }}$ at $0.83 M_{\text {exp }}$

*inconsistent rotation measurement. 
1 Table 2-Summary of properties and results of interior slab-column specimens tested 2 under constant vertical load and cyclically increasing moment

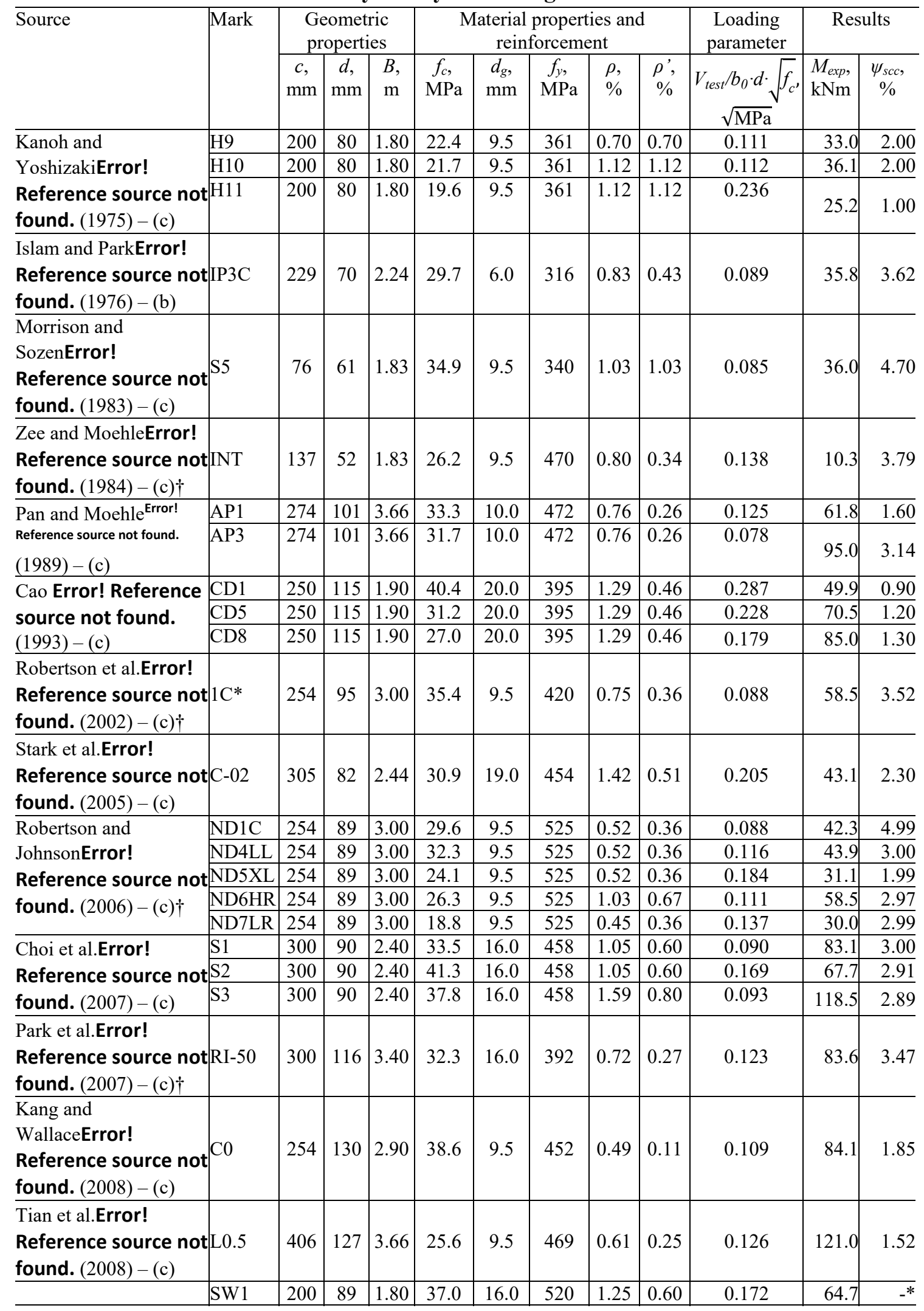




\begin{tabular}{|c|c|c|c|c|c|c|c|c|c|c|c|c|}
\hline $\begin{array}{l}\mathrm{Bu} \text { and PolakError! } \\
\text { Reference source not } \\
\text { found. }(2009)-\text { (c) }\end{array}$ & SW5 & 200 & 89 & 1.80 & 45.0 & 16.0 & 520 & 1.25 & 0.60 & 0.234 & 65.1 & -* \\
\hline $\begin{array}{l}\text { Cho Error! Reference } \\
\text { source not found. } \\
(2009)-(c)\end{array}$ & Control & 300 & 130 & 3.00 & 34.3 & 25.0 & 392 & 0.45 & 0.25 & 0.106 & 105.3 & 4.44 \\
\hline $\begin{array}{l}\text { Choi et al.Error! } \\
\text { Reference source not } \\
\text { found. }(2009)-(c) \dagger\end{array}$ & SPB & 355 & 106 & 4.20 & 34.1 & 16.0 & 440 & 1.24 & 0.35 & 0.106 & 137.4 & 3.68 \\
\hline Park et al.Error! & $\mathrm{RCA}$ & 250 & 106 & 2.70 & 22.5 & 9.5 & 430 & 1.06 & 0.79 & 0.171 & 70.8 & 1.24 \\
\hline $\begin{array}{l}\text { Reference source not } \\
\text { found. }(2012)-(c)\end{array}$ & $\mathrm{t}_{\mathrm{RCB}}$ & 300 & 106 & 2.70 & 38.7 & 9.5 & 430 & 1.06 & 0.79 & 0.157 & 74.0 & 1.37 \\
\hline Drakatos et al. ${ }^{\text {Error! }}$ & PD2 & 390 & 198 & 3.00 & 36.9 & 16.0 & 558 & 0.81 & 0.34 & 0.262 & 196.0 & 0.36 \\
\hline Reference source not found. & PD6 & 390 & 199 & 3.00 & 38.3 & 16.0 & 507 & 0.81 & 0.30 & 0.170 & 372.0 & 0.86 \\
\hline \multirow{3}{*}{$(2016)-(b)$} & PD8 & 390 & 198 & 3.00 & 32.7 & 16.0 & 575 & 0.81 & 0.29 & 0.126 & 384.0 & 1.30 \\
\hline & PD11 & 390 & 196 & 3.00 & 33.1 & 16.0 & 593 & 1.60 & 0.71 & 0.280 & 286.0 & 0.43 \\
\hline & PD13 & 390 & 196 & 3.00 & 36.5 & 16.0 & 546 & 1.60 & 0.72 & 0.178 & 410.0 & 0.86 \\
\hline
\end{tabular}

$\dagger$ Test using setup (c) with the vertical load applied on the slab, for which the measured drift corresponds to the rotation due to slab deformation, i.e. the sum of $\psi_{s c c}$ and the slab rotation outside $r=0.22 L$. (Note: $1 \mathrm{~m}=3.18 \mathrm{ft}$ ) *inconsistently high drift measurement (communication with the authors)

2 Table 3-Summary of properties, dimensions and results for interior slab-column 3 specimens tested under constant eccentricity and monotonically increasing moment

\begin{tabular}{|c|c|c|c|c|c|c|c|c|c|c|c|c|}
\hline \multirow[t]{2}{*}{ Source } & \multirow[t]{2}{*}{ Mark } & \multicolumn{3}{|c|}{$\begin{array}{l}\text { Geometric } \\
\text { properties }\end{array}$} & \multicolumn{5}{|c|}{$\begin{array}{l}\text { Material properties and } \\
\text { reinforcement }\end{array}$} & \multirow[b]{2}{*}{$\begin{array}{c}e, \\
\mathrm{~mm}\end{array}$} & \multicolumn{2}{|c|}{ Results } \\
\hline & & $\begin{array}{c}c, \\
\mathrm{~mm}\end{array}$ & $\begin{array}{c}d, \\
\mathrm{~mm}\end{array}$ & $\begin{array}{l}B, \\
\mathrm{~m}\end{array}$ & $\begin{array}{c}f_{c}, \\
\mathrm{MPa}\end{array}$ & $\begin{array}{c}d_{g}, \\
\mathrm{~mm}\end{array}$ & $\begin{array}{c}f_{y} \\
\mathrm{MPa}\end{array}$ & $\begin{array}{l}\rho, \\
\%\end{array}$ & $\begin{array}{l}\rho \\
\% \\
\%\end{array}$ & & $\begin{array}{l}V_{\text {exp }}, \\
\mathrm{kN}\end{array}$ & $\psi_{\max }$ \\
\hline \multirow{2}{*}{$\begin{array}{l}\text { Elstner and } \\
\text { Hognestad }^{40} \\
(1956)-(a) \dagger\end{array}$} & A11 & 356 & 114 & 1.83 & 25.9 & 25.4 & 326 & 2.47 & 1.15 & 178 & 529.0 & 1.39 \\
\hline & A12 & 356 & 114 & 1.83 & 28.4 & 25.4 & 326 & 2.47 & 2.47 & 178 & 529.0 & 1.39 \\
\hline \multirow{9}{*}{$\begin{array}{l}\operatorname{Moe}^{41}(1961)- \\
\text { (a) }\end{array}$} & M2 & 305 & 114 & 1.83 & 25.7 & 9.5 & 481 & 1.50 & - & 196 & 292.2 & - \\
\hline & M2A & 305 & 114 & 1.83 & 15.5 & 9.5 & 481 & 1.50 & - & 185 & 212.6 & - \\
\hline & \begin{tabular}{|l|} 
M3 \\
\end{tabular} & 305 & 114 & 1.83 & 22.8 & 9.5 & 481 & 1.50 & - & 338 & 207.3 & - \\
\hline & M4A & 305 & 114 & 1.83 & 17.7 & 9.5 & 481 & 1.50 & - & 434 & 143.7 & - \\
\hline & M6 & 254 & 122 & 1.83 & 26.5 & 9.5 & 327 & 1.34 & - & 168 & 239.3 & - \\
\hline & M7 & 254 & 122 & 1.83 & 25.0 & 9.5 & 327 & 1.34 & - & 61 & 311.0 & - \\
\hline & M8 & 254 & 122 & 1.83 & 24.6 & 9.5 & 327 & 1.34 & 0.57 & 437 & 149.5 & - \\
\hline & M9 & 254 & 122 & 1.83 & 23.2 & 9.5 & 327 & 1.34 & - & 127 & 266.9 & - \\
\hline & M10 & 254 & 122 & 1.83 & 21.1 & 9.5 & 327 & 1.34 & 0.57 & 308 & 177.9 & - \\
\hline \multirow{5}{*}{$\begin{array}{l}\operatorname{Anis}^{42}(1970)- \\
\text { (a) }\end{array}$} & B3 & 203 & 76 & 1.47 & 30.4 & 9.5 & 331 & 2.19 & - & 94 & 191.3 & - \\
\hline & B4 & 203 & 76 & 1.47 & 29.8 & 9.5 & 331 & 2.19 & - & 188 & 139.7 & - \\
\hline & B5 & 203 & 76 & 1.47 & 29.0 & 9.5 & 331 & 2.19 & - & 313 & 125.4 & - \\
\hline & B6 & 203 & 76 & 1.47 & 31.3 & 9.5 & 331 & 2.19 & - & 464 & 115.7 & - \\
\hline & B7 & 203 & 76 & 1.47 & 33.8 & 9.5 & 331 & 2.19 & - & 737 & 69.8 & - \\
\hline $\begin{array}{l}\text { Narasimhan }^{43} \\
(1971)-(a)\end{array}$ & L1 & 305 & 143 & 2.28 & 33.8 & 9.5 & 398 & 1.11 & - & 305 & 399.0 & - \\
\hline \multirow{9}{*}{$\begin{array}{l}\text { Hawkins et al. } \\
(1989)-(b) \dagger\end{array}$} & $6 \mathrm{AH}$ & 305 & 121 & 1.83 & 31.3 & 19.0 & 472 & 0.60 & 0.28 & 535 & 169.0 & 5.55 \\
\hline & 9.6AH & 305 & 118 & 1.83 & 30.7 & 19.0 & 415 & 0.79 & 0.50 & 522 & 187.0 & 4.02 \\
\hline & $14 \mathrm{AH}$ & 305 & 114 & 1.83 & 30.3 & 19.0 & 420 & 1.26 & 0.63 & 489 & 205.0 & 3.19 \\
\hline & $6 \mathrm{AL}$ & 305 & 121 & 1.83 & 22.7 & 19.0 & 472 & 0.60 & 0.28 & 135 & 244.0 & 3.19 \\
\hline & $9.6 \mathrm{AL}$ & 305 & 118 & 1.83 & 28.9 & 19.0 & 415 & 0.79 & 0.50 & 135 & 257.0 & 2.64 \\
\hline & $14 \mathrm{AL}$ & 305 & 114 & 1.83 & 27.0 & 19.0 & 420 & 1.26 & 0.63 & 136 & 319.0 & 2.22 \\
\hline & $7.3 \mathrm{BH}$ & 305 & 82 & 1.83 & 22.2 & 19.0 & 472 & 0.64 & 0.40 & 488 & 80.0 & 4.16 \\
\hline & $9.5 \mathrm{BH}$ & 305 & 83 & 1.83 & 19.8 & 19.0 & 472 & 0.79 & 0.51 & 483 & 94.0 & 4.72 \\
\hline & $14.2 \mathrm{BH}$ & 305 & 79 & 1.83 & 29.5 & 19.0 & 415 & 1.22 & 0.76 & 500 & 102.0 & 3.19 \\
\hline
\end{tabular}




\begin{tabular}{|c|c|c|c|c|c|c|c|c|c|c|c|c|}
\hline \multirow[t]{15}{*}{ Source } & \multirow[t]{2}{*}{ Mark } & \multicolumn{3}{|c|}{$\begin{array}{l}\text { Geometric } \\
\text { properties }\end{array}$} & \multicolumn{5}{|c|}{$\begin{array}{l}\text { Material properties and } \\
\text { reinforcement }\end{array}$} & \multirow[b]{2}{*}{$\begin{array}{c}e, \\
\mathrm{~mm}\end{array}$} & \multicolumn{2}{|c|}{ Results } \\
\hline & & $\begin{array}{c}c \\
\mathrm{~mm}\end{array}$ & $\begin{array}{c}d, \\
\mathrm{~mm}\end{array}$ & $\begin{array}{l}B, \\
\mathrm{~m}\end{array}$ & $\begin{array}{c}f_{c}, \\
\mathrm{MPa}\end{array}$ & $\begin{array}{l}d_{g}, \\
\mathrm{~mm}\end{array}$ & $\begin{array}{l}f_{y}, \\
\mathrm{MPa}\end{array}$ & $\begin{array}{l}\rho, \\
\%\end{array}$ & $\begin{array}{l}\rho^{\prime} \\
\%\end{array}$ & & $\begin{array}{l}V_{\exp }, \\
\mathrm{kN}\end{array}$ & $\begin{array}{l}\psi_{\max }, \\
\%\end{array}$ \\
\hline & 7.3BL & 305 & 83 & 1.83 & 18.1 & 19.0 & 472 & 0.64 & 0.40 & 98 & 130.0 & 3.89 \\
\hline & $9.5 \mathrm{BL}$ & 305 & 83 & 1.83 & 20.0 & 19.0 & 472 & 0.79 & 0.51 & 117 & 142.0 & 4.16 \\
\hline & $14.2 \mathrm{BL}$ & 305 & 76 & 1.83 & 20.5 & 19.0 & 415 & 1.22 & 0.76 & 129 & 162.0 & 3.47 \\
\hline & $6 \mathrm{CH}$ & 305 & 121 & 1.83 & 52.4 & 19.0 & 472 & 0.60 & 0.28 & 511 & 186.0 & 6.24 \\
\hline & $9.6 \mathrm{CH}$ & 305 & 117 & 1.83 & 57.2 & 19.0 & 415 & 0.87 & 0.50 & 519 & 218.0 & 3.14 \\
\hline & $14 \mathrm{CH}$ & 305 & 114 & 1.83 & 54.7 & 19.0 & 420 & 1.16 & 0.63 & 529 & 252.0 & 3.05 \\
\hline & 6CL & 305 & 121 & 1.83 & 49.5 & 19.0 & 472 & 0.60 & 0.28 & 135 & 273.0 & 4.72 \\
\hline & $14 \mathrm{CL}$ & 305 & 114 & 1.83 & 47.7 & 19.0 & 420 & 1.16 & 0.63 & 136 & 362.0 & 2.36 \\
\hline & $14 \mathrm{FH}$ & 305 & 114 & 1.83 & 31.2 & 19.0 & 446 & 0.90 & 0.22 & 498 & 206.0 & 2.58 \\
\hline & 6FLI & 305 & 120 & 1.83 & 25.9 & 19.0 & 472 & 0.59 & 0.27 & 119 & 227.0 & 3.15 \\
\hline & 10.2FLI & 305 & 114 & 1.83 & 18.1 & 19.0 & 446 & 1.13 & 0.49 & 112 & 240.0 & 1.94 \\
\hline & 10.2FLO & 305 & 114 & 1.83 & 26.5 & 19.0 & 446 & 0.77 & 0.49 & 121 & 290.0 & 2.78 \\
\hline & $10.2 \mathrm{FHO}$ & 305 & 121 & 1.83 & 33.8 & 19.0 & 446 & 0.77 & 0.49 & 491 & 183.0 & 3.05 \\
\hline \multirow{4}{*}{$\begin{array}{l}\text { Kamaraldin } 45 \\
(1990)-(a)\end{array}$} & SA1 & 150 & 64 & 2.00 & 33.0 & 10.0 & 640 & 0.55 & 0.55 & 52 & 105.0 & - \\
\hline & SA3 & 150 & 64 & 2.00 & 36.0 & 10.0 & 640 & 0.55 & 0.55 & 100 & 85.0 & - \\
\hline & SA4 & 150 & 64 & 2.00 & 32.0 & 10.0 & 640 & 0.55 & 0.55 & 336 & 49.0 & - \\
\hline & SB2 & 150 & 62 & 2.00 & 28.0 & 10.0 & 640 & 1.00 & 1.00 & 360 & 61.0 & - \\
\hline \multirow{5}{*}{$\begin{array}{l}\text { Marzouk et al. }{ }^{46} \\
(1996)-(b)\end{array}$} & NHLS0.5 & 250 & 119 & 1.87 & 43.2 & 19.0 & 450 & 0.50 & 0.28 & 167 & 266.2 & - \\
\hline & NHLS1.0 & 250 & 119 & 1.87 & 42.7 & 19.0 & 450 & 1.00 & 0.38 & 130 & 408.2 & - \\
\hline & NNHS0.5 & 250 & 119 & 1.87 & 36.2 & 19.0 & 450 & 1.00 & 0.38 & 720 & 163.6 & - \\
\hline & NHHS0.5 & 250 & 119 & 1.87 & 34.0 & 19.0 & 450 & 0.50 & 0.28 & 595 & 164.3 & - \\
\hline & NHHS1.0 & 250 & 119 & 1.87 & 35.3 & 19.0 & 450 & 1.00 & 0.38 & 464 & 250.3 & - \\
\hline \multirow{2}{*}{$\begin{array}{l}\text { Krüger et al. }{ }^{47} \\
(2000)-(a) \dagger\end{array}$} & P16A & 300 & 121 & 3.00 & 38.6 & 16.0 & 460 & 1.00 & - & 160 & 332.0 & 1.26 \\
\hline & P32 & 300 & 121 & 3.00 & 30.4 & 16.0 & 460 & 1.00 & - & 320 & 270.0 & 0.76 \\
\hline $\begin{array}{l}\text { Binici and } \\
\text { Bayrak }^{48}(2005) \\
-(\mathrm{a}) \dagger\end{array}$ & $\mathrm{CE}$ & 150 & 57 & 1.02 & 24.1 & 9.5 & 455 & 1.38 & 0.70 & 150 & 95.6 & 2.25 \\
\hline \multirow{2}{*}{$\begin{array}{l}\text { Ben Sasi }{ }^{49} \\
(2012)-(a)\end{array}$} & SI-1 & 180 & 60 & 1.00 & 28.1 & 12.0 & 335 & 1.40 & 1.40 & 280 & 65.0 & - \\
\hline & SI-2 & 180 & 60 & 1.00 & 25.0 & 12.0 & 335 & 1.40 & 1.40 & 580 & 37.5 & - \\
\hline
\end{tabular}

1

3

\section{Additional references (tests under constant eccentricity)} ACI Journal, Proceedings V. 53, No. 2, Feb. 1956, pp. 29-58. Laboratories, Skokie, IL, 1961, 135 pp. Kingdom, 1970, 265 pp.

$\dagger$ Maximum slab rotations, calculated from edge deflections, are reported

40. Elstner, R. C., and Hognestad, E., "Shearing Strength of Reinforced Concrete Slabs,"

41. Moe, J., "Shearing Strength of Reinforced Concrete Slabs and Footings under Concentrated Loads," Bulletin D46, Portland Cement Association, Research and Development

42. Anis, N.N., "Shear Strength of Reinforced Concrete Flat Slabs Without Shear Reinforcement," doctoral thesis, Imperial College of Science and Technology, London, United 
1 43. Narasimhan, N., "Shear Reinforcement in Reinforced Concrete Column Heads," 2 doctoral thesis, Imperial College of Science and Technology, London, United Kingdom, 1971, $3268 \mathrm{pp}$.

4 44. Hawkins, N.; Bao, A.; and Yamazaki, J., "Moment Transfer from Concrete Slabs to 5 Columns," ACI Structural Journal, V. 86, No. 6, Nov.-Dec. 1989, pp. 705-716.

6 45. Kamaraldin, K., "Punching Shear and Moment Transfer in Reinforced Concrete Flat 7 Slabs," doctoral thesis, The Polytechnic of Central London, London, United Kingdom, 1990, $8287 \mathrm{pp}$.

9 46. Marzouk, H.; Emam, M.; and Hilal, M.S., "Effect of High-Strength Concrete Columns 10 on the Behavior of Slab-Column Connections," ACI Structural Journal, V. 93, No. 5, Sept.11 Oct. 1996, pp. 545-552.

12 47. Krüger, G., "Eccentric Punching Resistance of Flat Slabs," doctoral thesis, No. 2064, 13 EPFL, Lausanne, Switzerland, 1999, 191 pp. (in French)

14 48. Binici, B., and Bayrak, O., "Upgrading of Slab-Column Connections using Fiber 15 Reinforced Polymers,” Engineering Structures, V. 27, No. 1, Oct. 2004, pp. 97-107.

16 49. Ben-Sasi, O.M., "Tests of Interior Flat Slab-Column Connections Transferring Shear 17 Force and Moment," $37^{\text {th }}$ Conference on Our World in Concrete \& Structures, Singapore, Aug. 182012. 
3 Table 4-Moment resistance and deformation capacity predictions for interior slab4 column specimens tested under constant vertical load and monotonically increasing 5 moment

\begin{tabular}{|c|c|c|c|c|c|c|}
\hline \multirow[t]{2}{*}{ Source } & \multirow[t]{2}{*}{ Mark } & \multicolumn{3}{|c|}{$M_{\text {pred }} / M_{\exp }(-)$} & \multicolumn{2}{|c|}{$\psi_{\text {scc.pred }} / \psi_{\text {scc.exp }}(-)$} \\
\hline & & $\begin{array}{l}\text { CSCT } \\
\text { (mono) }\end{array}$ & $\begin{array}{l}\text { ACI 318- } \\
14^{\text {Error! }} \\
\text { Reference } \\
\text { source not } \\
\text { found. }\end{array}$ & $\begin{array}{l}\text { Broms }^{\text {Error! }} \\
\text { Reference } \\
\text { source not } \\
\text { found. }\end{array}$ & $\begin{array}{l}\text { CSCT } \\
\text { (mono) }\end{array}$ & $\begin{array}{l}\text { Broms } \\
\text { Refror! } \\
\text { source not } \\
\text { found. }\end{array}$ \\
\hline \multirow{2}{*}{$\begin{array}{l}\text { Ghali et al.Error! } \\
\text { Reference source not } \\
\text { found. }(1974)-(c)\end{array}$} & B3NP & 0.948 & 0.554 & 0.913 & - & - \\
\hline & $\mathrm{B} 5 \mathrm{NP}$ & 0.817 & 0.517 & 0.870 & - & \\
\hline \multirow{4}{*}{$\begin{array}{l}\text { Stamenkovic and } \\
\text { ChapmanError! Reference } \\
\text { source not found. (1974) } \\
\text {-(c) }\end{array}$} & $\mathrm{C} / \mathrm{I} / 1$ & 0.832 & 0.618 & 1.021 & - & - \\
\hline & $\mathrm{C} / \mathrm{I} / 2$ & 0.984 & 0.560 & 1.215 & - & - \\
\hline & $\mathrm{C} / \mathrm{I} / 3$ & 1.059 & 0.569 & 1.347 & - & - \\
\hline & $\mathrm{C} / \mathrm{I} / 4$ & 0.962 & 0.533 & 1.229 & - & - \\
\hline \multirow{3}{*}{$\begin{array}{l}\text { Ghali et al.Error! } \\
\text { Reference source not } \\
\text { found. }(1976)-(c)\end{array}$} & SM0.5 & 1.009 & 0.619 & 1.000 & 0.928 & 2.221 \\
\hline & SM1.0 & 0.979 & 0.807 & 1.018 & 0.762 & 1.049 \\
\hline & SM1.5 & 1.268 & 0.838 & 1.046 & 1.063 & 1.102 \\
\hline \multirow{2}{*}{$\begin{array}{l}\text { Islam and ParkError! } \\
\text { Reference source not } \\
\text { found. }(1976)-(b)\end{array}$} & IP1 & 1.084 & 0.611 & 1.621 & 1.137 & 3.194 \\
\hline & IP2 & 0.926 & 0.519 & 1.412 & 1.094 & 3.111 \\
\hline $\begin{array}{l}\text { Elgabry and GhaliError! } \\
\text { Reference source not } \\
\text { found. }(1987)-(\mathrm{c})\end{array}$ & 1 & 1.061 & 0.627 & 0.950 & $1.054 \neq$ & - \\
\hline \multirow{6}{*}{$\begin{array}{l}\text { Drakatos et al. } \\
\text { source not found. } \\
(2016)-(b)\end{array}$} & PD1 & 1.070 & 0.766 & 0.826 & $-*$ & $-*$ \\
\hline & PD3 & 1.066 & 0.767 & 0.985 & 0.981 & 2.369 \\
\hline & PD4 & 0.975 & 0.691 & 0.856 & 0.876 & 1.099 \\
\hline & PD5 & 1.021 & 0.640 & 0.898 & 0.545 & 0.874 \\
\hline & PD10 & 1.170 & 0.662 & 0.836 & 0.886 & 0.661 \\
\hline & PD12 & 1.094 & 0.617 & 0.736 & 0.721 & 0.705 \\
\hline Mean (all tests) & & 1.018 & 0.640 & 1.043 & 0.913 & 1.639 \\
\hline Mean $(d>0.1 \mathrm{~m})$ & & 1.040 & 0.675 & 0.911 & 0.869 & 1.260 \\
\hline COV (all tests) & & 0.107 & 0.154 & 0.224 & 0.198 & 0.603 \\
\hline $\operatorname{COV}(d>0.1 \mathrm{~m})$ & & 0.109 & 0.149 & 0.101 & 0.194 & 0.525 \\
\hline
\end{tabular}

$1 \mathrm{~m}=3.28 \mathrm{ft}$

$\neq \psi_{\max }$ at $0.83 M_{\exp }$

*inconsistent rotation measurement 
1 Table 5-Moment resistance and deformation capacity predictions for interior slab2 column specimens tested under constant vertical load and cyclically increasing moment

\begin{tabular}{|c|c|c|c|c|c|c|}
\hline \multirow[t]{2}{*}{ Source } & \multirow[t]{2}{*}{ Mark } & \multicolumn{2}{|c|}{$M_{\text {pred }} / M_{\exp }(-)$} & \multicolumn{3}{|c|}{$\psi_{\text {scc.pred }} / \psi_{\text {scc.exp }}(-)$} \\
\hline & & $\begin{array}{l}\mathrm{CSCT} \\
\text { (cyc) }\end{array}$ & $\begin{array}{l}\text { ACI 318- } \\
14^{\text {Error! }} \\
\text { Reference } \\
\text { source not } \\
\text { found. }\end{array}$ & $\begin{array}{l}\text { CSCT } \\
\text { (cyc) }\end{array}$ & $\begin{array}{l}\text { ACI 318- } \\
14^{\text {Error! }} \\
\text { Reference } \\
\text { source not } \\
\text { found. }\end{array}$ & $\begin{array}{l}\text { Hueste \& } \\
\text { Wight Error } \\
\text { ! Reference } \\
\text { source not } \\
\text { found. }\end{array}$ \\
\hline \multirow{3}{*}{$\begin{array}{l}\text { Kanoh and YoshizakiError! } \\
\text { Reference source not } \\
\text { found. }(1975)-(\text { c) }\end{array}$} & H9 & 1.094 & 0.746 & 1.040 & 0.970 & 1.300 \\
\hline & $\mathrm{H} 10$ & 1.027 & 0.704 & 0.970 & 0.958 & 1.270 \\
\hline & H11 & 1.007 & 0.676 & 1.012 & 0.500 & 1.056 \\
\hline $\begin{array}{l}\text { Islam and ParkError! } \\
\text { Reference source not } \\
\text { found. }(1976)-(b)\end{array}$ & IP3C & 1.012 & 0.462 & 0.843 & 0.641 & 0.982 \\
\hline $\begin{array}{l}\text { Morrison and SozenError! } \\
\text { Reference source not } \\
\text { found. }(1983)-(\mathrm{c})\end{array}$ & S5 & 0.924 & 0.639 & 0.963 & 0.559 & \\
\hline $\begin{array}{l}\text { Zee and MoehleError! } \\
\text { Reference source not } \\
\text { found. }(1984)-(\mathrm{c}) \ddagger\end{array}$ & INT & 0.954 & 0.729 & 0.964 & 0.410 & 0.431 \\
\hline \multirow{2}{*}{$\begin{array}{l}\text { Pan and Moehle Error! Reference } \\
\text { source not found. }(1989)-\text { (c) }\end{array}$} & AP1 & 0.986 & 0.898 & 0.917 & 1.079 & 1.292 \\
\hline & AP3 & 1.032 & 0.584 & 0.882 & 0.765 & 1.195 \\
\hline \multirow{3}{*}{$\begin{array}{l}\text { CaoError! Reference } \\
\text { source not found. (1993) } \\
- \text { (c) }\end{array}$} & CD1 & 0.931 & 0.789 & 0.897 & 0.556 & 0.917 \\
\hline & CD5 & 0.992 & 0.693 & 0.899 & 0.417 & 0.918 \\
\hline & CD8 & 0.937 & 0.649 & 0.875 & 0.761 & 1.023 \\
\hline $\begin{array}{l}\text { Robertson et al.Error! } \\
\text { Reference source not } \\
\text { found. }(2002)-(\mathrm{c}) \ddagger \\
\end{array}$ & $1 \mathrm{C}$ & 1.011 & 0.991 & 1.208 & 0.640 & 0.961 \\
\hline $\begin{array}{l}\text { Stark et al.Error! } \\
\text { Reference source not } \\
\text { found. (2005)-(c) }\end{array}$ & C-02 & 0.883 & 0.939 & 0.988 & 0.444 & 0.583 \\
\hline \multirow{5}{*}{$\begin{array}{l}\text { Robertson and } \\
\text { JohnsonError! Reference } \\
\text { source not found. (2006) } \\
-(\text { c) } \ddagger\end{array}$} & ND1C & 0.992 & 0.560 & 0.975 & 0.466 & 0.715 \\
\hline & ND4LL & 0.941 & 0.512 & 0.988 & 0.635 & 0.837 \\
\hline & ND5XL & 0.937 & 0.564 & 1.090 & 0.485 & 0.662 \\
\hline & ND6HR & 0.957 & 0.774 & 0.986 & 0.650 & 0.868 \\
\hline & ND7LR & 0.925 & 0.635 & 0.987 & 0.522 & 0.552 \\
\hline \multirow{3}{*}{$\begin{array}{l}\text { Choi et al.Error! } \\
\text { Reference source not } \\
\text { found. (2007) - (c) }\end{array}$} & S1 & 0.998 & 0.780 & 1.033 & 0.772 & 1.181 \\
\hline & S2 & 0.810 & 0.879 & 0.809 & 0.442 & 0.491 \\
\hline & S3 & 0.881 & 0.663 & 0.902 & 0.790 & 1.196 \\
\hline $\begin{array}{l}\text { Park et al.Error! Reference } \\
\text { source not found. (2007) } \\
-(\mathrm{c}) \neq\end{array}$ & RI-50 & 0.955 & 0.719 & 1.025 & 0.535 & 0.690 \\
\hline $\begin{array}{l}\text { Kang and WallaceError! } \\
\text { Reference source not } \\
\text { found. }(2008)-(\mathrm{c})\end{array}$ & $\mathrm{C} 0$ & 0.817 & 0.963 & 0.814 & 1.074 & 1.469 \\
\hline $\begin{array}{l}\text { Tian et al.Error! Reference } \\
\text { source not found. (2008) } \\
- \text { (c) }\end{array}$ & L0.5 & 1.001 & 0.690 & 1.121 & 1.180 & 1.469 \\
\hline \multirow{2}{*}{$\begin{array}{l}\text { Bu and PolakError! } \\
\text { Reference source not } \\
\text { found. }(2009)-(\mathrm{c})\end{array}$} & SW1 & 0.881 & 0.567 & -* & -* & -* \\
\hline & SW5 & 0.775 & 0.547 & $-*$ & $-*$ & $-*$ \\
\hline
\end{tabular}




\begin{tabular}{|c|c|c|c|c|c|c|}
\hline $\begin{array}{l}\text { ChoError! Reference } \\
\text { source not found. (2009) } \\
-(\mathrm{c}) \neq\end{array}$ & Control & 0.897 & 0.799 & 0.916 & 0.452 & 0.623 \\
\hline $\begin{array}{l}\text { Choi et al.Error! } \\
\text { Reference source not } \\
\text { found. }(2009)-(c) \neq\end{array}$ & SPB & 0.988 & 0.864 & 0.930 & 0.654 & 1.023 \\
\hline \multirow{2}{*}{$\begin{array}{l}\text { Park et al.Error! Reference } \\
\text { source not found. (2012) } \\
-(\mathrm{c})\end{array}$} & RCA & 0.956 & 0.798 & 0.987 & 0.865 & 1.095 \\
\hline & $\mathrm{RCB}$ & 1.052 & 0.945 & 1.190 & 0.927 & 1.039 \\
\hline \multirow{5}{*}{$\begin{array}{l}\text { Drakatos et al. } \\
\text { source not found. }(2016)-(b)\end{array}$} & PD2 & 1.009 & 0.795 & 1.132 & 1.389 & 2.260 \\
\hline & PD6 & 0.971 & 0.728 & 0.918 & 0.829 & 1.439 \\
\hline & PD8 & 0.980 & 0.736 & 0.766 & 0.993 & 1.100 \\
\hline & PD11 & 0.928 & 0.639 & 0.721 & 1.163 & 1.670 \\
\hline & PD13 & 1.007 & 0.654 & 0.718 & 0.680 & 1.389 \\
\hline Mean (all tests) & & 0.956 & 0.723 & 0.954 & 0.733 & 1.053 \\
\hline Mean $(d>0.1 \mathrm{~m})$ & & 0.967 & 0.761 & 0.924 & 0.842 & 1.212 \\
\hline COV (all tests) & & 0.072 & 0.185 & 0.124 & 0.351 & 0.364 \\
\hline $\operatorname{COV}(d>0.1 \mathrm{~m})$ & & $\mathbf{0 . 0 5 7}$ & 0.144 & 0.147 & 0.332 & 0.320 \\
\hline
\end{tabular}

‡ Rotation due to slab deformation $\psi_{\text {slab }}$ for tests using setup (c) with the vertical load applied on the slab (to account for simply supported slabs the first term " 2 " in Eq. Error! Reference source not found. is replaced by " 3 ", the second term " 2 "and the term "3" are omitted )

*inconsistently high drift measurement (communication with the authors)

$1 \mathrm{~m}=3.18 \mathrm{ft}$

\section{APPENDIX 6}

2 As can be seen from Figure A7(a), in average the predictions of ACI 318-14 ${ }^{\text {Error! Reference source }}$

3 not found. for the shear strength (or equally the moment capacity) of slabs subjected to constant

4 eccentricity are rather conservative (ratio of predicted to observed values: $0.76 \pm 0.24$ ). For

5 eccentricities $e$ both higher and lower than the column size $c$ ACI 318-14 Error! Reference source not

6 found. slightly overestimates the shear strength for tests with low values of gravity load at failure

7 and tends to underestimate the shear strength for tests with intermediate and high values of

8 gravity induced shear at failure. Broms' model ${ }^{\text {Error! Reference source not found. }}$ shows the same trend

9 but with significant strength overestimation (1.07 \pm 0.19$)$, in particular for low vertical loads at

10 failure (Fig. A7(b)). For the predictions of the proposed model combined with CSCT(mono)

11 (Fig. A7(c)) this trend can still be visible but the mean value of the ratio $V_{\text {pred }} / V_{\text {exp }}$ falls to 1.01

12 and the scatter is significantly reduced $(\mathrm{COV}=10 \%)$. 

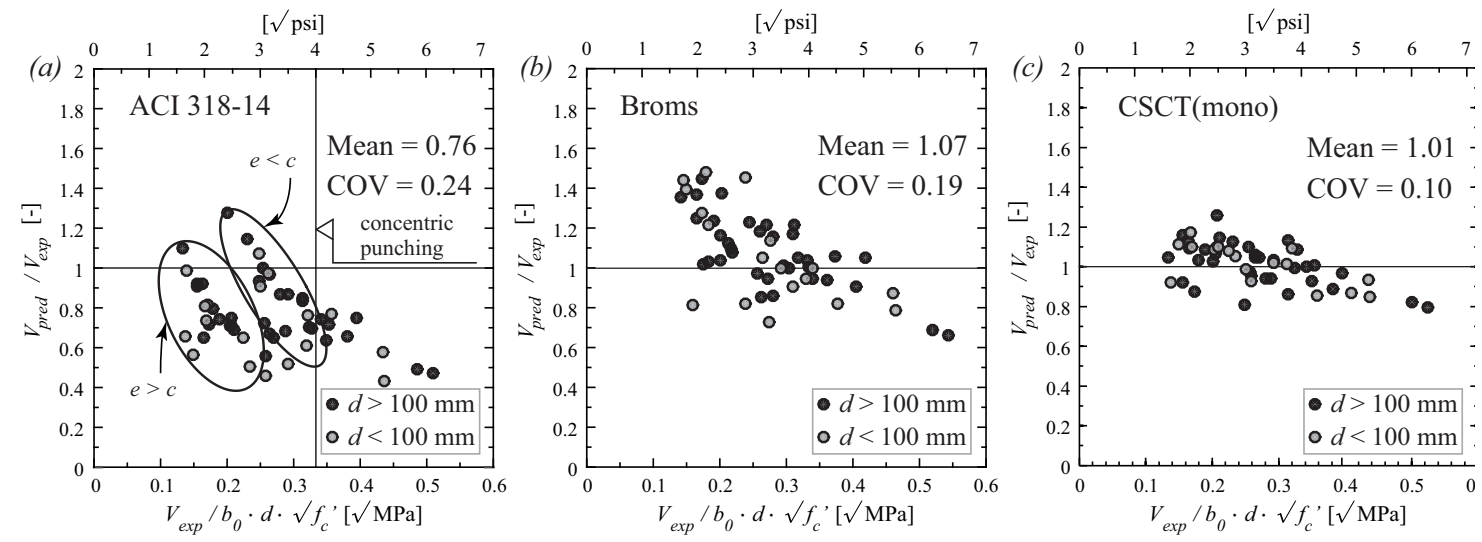

Fig. A7 - Shear strength predictions for specimens subjected to constant eccentricity and monotonically increasing shear force according to: (a) ACI 318-14

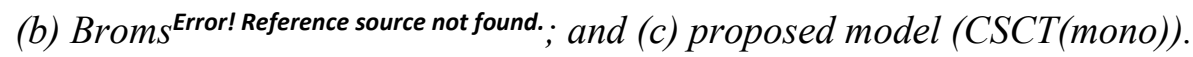

Figure A8 presents the predictions of the proposed model as ratio of calculated to measured

3 maximum local slab rotation at peak moment for tests conducted under constant eccentricity

4 for which the experimental values are reported. Since the reported rotations are local and both

5 ACI 318-14 Error! Reference source not found. and the model developed by Broms ${ }^{\text {Error! Reference source not }}$ found. provide global ultimate rotations, direct comparison of their performance with regard to

7 the proposed model is not possible. Moreover, ACI 318-14 Error! Reference source not found. provides

8 estimates of the deformation capacity of slab-column connections subjected to cyclic loading.

9 Therefore, no comparison with monotonic test results was performed.

10 As can be seen from Figure A8 calculating using the failure criterion that accounts for shear 11 redistribution (Fig. A8(a)) renders the predictions of the maximum local slab rotation at peak

12 moment less conservative in average as compared to the calculation using the CSCT(cyc)

13 failure criterion (ratio of predicted to observed values: $0.99 \pm 0.13$ and $0.79 \pm 0.13$, 14 respectively). 

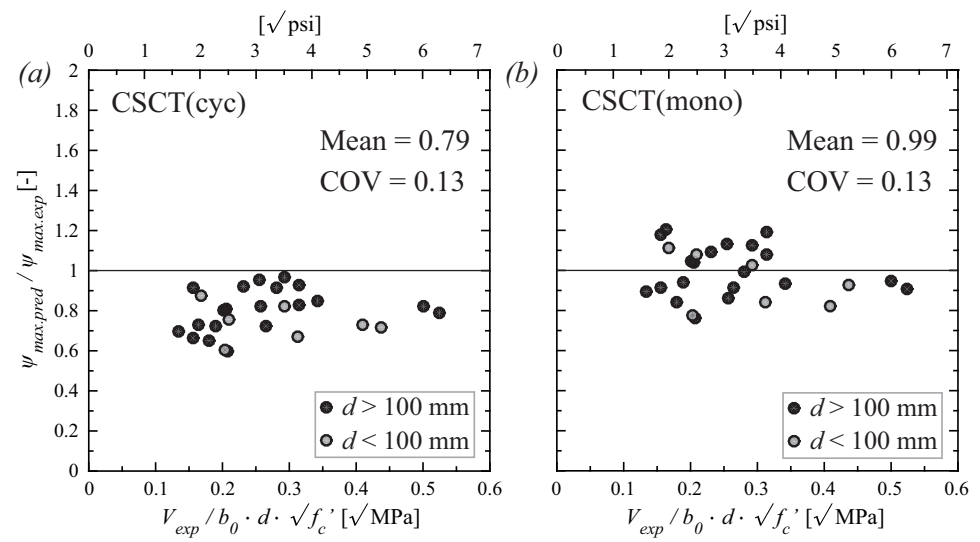

Fig. A8 - Predictions of maximum local slab rotation at peak moment for specimens subjected to constant eccentricity and monotonically increasing shear force according to the proposed model combined with: (a) CSCT(cyc); and (b) CSCT(mono). 
1 Table 6-Strength and deformation capacity predictions for interior slab-column 2 specimens tested under constant eccentricity and monotonically increasing moment

\begin{tabular}{|c|c|c|c|c|c|c|c|}
\hline \multirow[t]{2}{*}{ Source } & \multirow[t]{2}{*}{ Mark } & \multicolumn{4}{|c|}{$V_{\text {pred }} / V_{\exp }(-)$} & \multicolumn{2}{|c|}{$\psi_{\text {max.pred }} / \psi_{\text {max.exp }}(-)$} \\
\hline & & $\begin{array}{l}\text { CSCT } \\
\text { (mono) }\end{array}$ & $\begin{array}{l}\text { CSCT } \\
\text { (cyc) }\end{array}$ & $\begin{array}{c}\text { ACI } \\
318- \\
14^{\text {Error! }} \\
\text { Reference } \\
\text { source not } \\
\text { found. }\end{array}$ & $\begin{array}{c}\begin{array}{c}\text { Broms } \\
\text { rror! }\end{array} \\
\text { Reference } \\
\text { source not } \\
\text { found. }\end{array}$ & $\begin{array}{l}\text { CSCT } \\
\text { (mono) }\end{array}$ & $\begin{array}{l}\text { CSCT } \\
\text { (cyc) }\end{array}$ \\
\hline \multirow{2}{*}{$\begin{array}{l}\text { Elstner and } \\
\text { Hognestad }^{40}(1956) \\
\text { - A }\end{array}$} & A11 & 0.796 & 0.744 & 0.472 & 0.664 & 0.906 & 0.791 \\
\hline & A12 & 0.825 & 0.768 & 0.494 & 0.690 & 0.950 & 0.820 \\
\hline \multirow[t]{9}{*}{$\mathrm{Moe}^{41}(1961)-\mathrm{A}$} & M2 & 0.927 & 0.819 & 0.638 & 0.945 & - & - \\
\hline & M2A & 1.088 & 0.961 & 0.695 & 1.054 & - & - \\
\hline & M3 & 1.049 & 0.832 & 0.672 & 0.973 & - & - \\
\hline & M4A & 1.260 & 0.966 & 0.748 & 1.041 & - & - \\
\hline & M6 & 0.991 & 0.892 & 0.703 & 1.218 & - & - \\
\hline & M7 & 0.965 & 0.930 & 0.748 & 1.055 & - & - \\
\hline & M8 & 1.147 & 0.937 & 0.690 & 1.378 & - & - \\
\hline & M9 & 1.003 & 0.945 & 0.714 & 1.057 & - & - \\
\hline & M10 & 1.048 & 0.893 & 0.651 & 1.185 & - & - \\
\hline \multirow[t]{5}{*}{$\operatorname{Anis}^{42}(1970)-A$} & $\mathrm{~B} 3$ & 0.932 & 0.880 & 0.577 & 0.874 & - & - \\
\hline & B4 & 1.095 & 1.008 & 0.609 & 1.002 & - & - \\
\hline & $\mathrm{B} 5$ & 1.017 & 0.861 & 0.518 & 0.905 & - & - \\
\hline & B6 & 0.925 & 0.759 & 0.457 & 0.733 & - & - \\
\hline & B7 & 1.115 & 0.876 & 0.567 & 0.812 & - & - \\
\hline $\begin{array}{l}\text { Narasimhan }^{43} \\
(1971)-\mathrm{A}\end{array}$ & L1 & 0.940 & 0.841 & 0.686 & 1.000 & - & - \\
\hline \multirow{22}{*}{$\begin{array}{l}\text { Hawkins et al. }{ }^{44} \\
(1989)-\text { B }\end{array}$} & $6 \mathrm{AH}$ & 0.918 & 0.888 & 0.909 & 1.252 & 0.915 & 0.663 \\
\hline & $9.6 \mathrm{AH}$ & 1.032 & 0.958 & 0.796 & 1.236 & 0.841 & 0.652 \\
\hline & $14 \mathrm{AH}$ & 1.101 & 0.942 & 0.713 & 1.082 & 0.762 & 0.596 \\
\hline & $6 \mathrm{AL}$ & 1.058 & 0.995 & 0.968 & 1.155 & 0.915 & 0.724 \\
\hline & $9.6 \mathrm{AL}$ & 1.098 & 1.060 & 1.002 & 1.218 & 1.133 & 0.951 \\
\hline & $14 \mathrm{AL}$ & 1.002 & 0.966 & 0.743 & 0.943 & 0.932 & 0.851 \\
\hline & $7.3 \mathrm{BH}$ & 1.172 & 1.061 & 0.988 & 1.396 & 1.115 & 0.877 \\
\hline & $9.5 \mathrm{BH}$ & 1.089 & 0.929 & 0.812 & 1.220 & 0.778 & 0.604 \\
\hline & $14.2 \mathrm{BH}$ & 1.096 & 0.870 & 0.809 & 1.276 & 1.078 & 0.755 \\
\hline & 7.3BL & 1.021 & 0.957 & 1.070 & 1.053 & 1.028 & 0.820 \\
\hline & $9.5 \mathrm{BL}$ & 1.015 & 0.934 & 0.971 & 1.138 & 0.841 & 0.673 \\
\hline & 14.2BL & 0.868 & 0.822 & 0.762 & 0.945 & 0.824 & 0.729 \\
\hline & $6 \mathrm{CH}$ & 1.044 & 1.024 & 1.098 & 1.355 & 0.894 & 0.697 \\
\hline & $9.6 \mathrm{CH}$ & 1.157 & 1.090 & 0.924 & 1.368 & 1.178 & 0.916 \\
\hline & $14 \mathrm{CH}$ & 1.089 & 0.949 & 0.744 & 1.166 & 0.941 & 0.725 \\
\hline & 6CL & 1.028 & 1.011 & 1.278 & 1.127 & 1.044 & 0.799 \\
\hline & $14 \mathrm{CL}$ & 1.036 & 0.988 & 0.870 & 1.169 & 1.127 & 0.966 \\
\hline & $14 \mathrm{FH}$ & 1.063 & 0.919 & 0.712 & 1.098 & 1.039 & 0.806 \\
\hline & 6FLI & 1.125 & 1.091 & 1.148 & 1.234 & 1.095 & 0.924 \\
\hline & 10.2FLI & 1.129 & 1.062 & 0.850 & 1.006 & 1.082 & 0.830 \\
\hline & $10.2 \mathrm{FLO}$ & 0.863 & 0.825 & 0.835 & 1.040 & 1.191 & 0.928 \\
\hline & $10.2 \mathrm{FHO}$ & 1.130 & 0.987 & 0.918 & 1.450 & 1.203 & 0.731 \\
\hline \multirow{4}{*}{$\begin{array}{l}\text { Kamaraldin }^{45} \\
(1990)-\mathrm{A}\end{array}$} & SA1 & 0.852 & 0.808 & 0.770 & 0.819 & - & - \\
\hline & SA3 & 0.987 & 0.944 & 0.910 & 1.003 & - & - \\
\hline & SA4 & 1.096 & 0.964 & 0.734 & 1.484 & - & - \\
\hline & SB2 & 1.051 & 0.883 & 0.503 & 0.820 & - & - \\
\hline \multirow{3}{*}{$\begin{array}{l}\text { Marzouk et al. }{ }^{46} \\
(1996)-B\end{array}$} & NHLS0.5 & 0.808 & 0.791 & 0.936 & 0.854 & - & - \\
\hline & NHLS1.0 & 0.886 & 0.813 & 0.657 & 0.906 & - & - \\
\hline & NNHS1.0 & 1.093 & 0.893 & 0.649 & 1.023 & & - \\
\hline
\end{tabular}




\begin{tabular}{|c|c|c|c|c|c|c|c|}
\hline \multirow[t]{4}{*}{ Source } & \multirow[t]{2}{*}{ Mark } & \multicolumn{4}{|c|}{$V_{\text {pred }} / V_{\exp }(-)$} & \multicolumn{2}{|c|}{$\psi_{\text {max.pred }} / \psi_{\text {max.exp }}(-)$} \\
\hline & & $\begin{array}{c}\text { CSCT } \\
\text { (mono) }\end{array}$ & $\begin{array}{l}\text { CSCT } \\
\text { (cyc) }\end{array}$ & $\begin{array}{c}\text { ACI } \\
318- \\
14^{\text {Error! }} \\
\text { Reference } \\
\text { source not } \\
\text { found. }\end{array}$ & $\begin{array}{c}\begin{array}{c}\text { Broms } \\
\text { rror! }\end{array} \\
\text { Reference } \\
\text { source not } \\
\text { found. }\end{array}$ & $\begin{array}{c}\text { CSCT } \\
\text { (mono) }\end{array}$ & $\begin{array}{c}\text { CSCT } \\
(\mathrm{cyc})\end{array}$ \\
\hline & NHHS0.5 & 0.877 & 0.831 & 0.713 & 1.033 & - & - \\
\hline & NHHS1.0 & 0.957 & 0.788 & 0.557 & 0.949 & - & - \\
\hline
\end{tabular}

1

3 The following symbols are used in the paper:

$4 \quad b_{0} \quad=$ perimeter of the critical section at $d / 2$ from the column

$5 \quad c \quad=$ side length or a diameter of the column

$6 \quad d \quad=$ effective depth of a slab (distance from the tension reinforcement to the extreme

7 compressed fibre)

$8 \quad d_{g}=$ maximum diameter of the aggregate

$9 d_{g 0}=$ reference aggregate size $(16 \mathrm{~mm}, 0.63 ”)$

$10 e \quad=$ ratio of inserted moment to applied vertical load on the slab-column connection

11 (eccentricity)

$12 e_{k}=$ ratio of inserted moment to applied vertical load on the slab-column connection

13 (eccentricity) at load step $k$

$14 f_{c}=$ average compressive strength of concrete (cylinder)

$15 f_{y} \quad=$ yield stess of reinforcing steel 
$1 \quad h \quad=$ slab thickness - beam height (Effective Beam Width Method)

$2 B=$ specimen size (for Table 1 and Table 2 )

$3 \quad L=$ distance between the axes of the columns in a continuous slab (slab span)

$4 \quad M_{\exp }=$ peak moment applied to the slab-column connection (moment strength)

$5 \quad M_{k} \quad=$ moment applied to the slab-column connection at load step $k$

$6 \quad M_{\text {pred }}=$ predicted peak moment acting on the slab-column connection

$7 n=$ number of sector elements

$8 \quad N=$ number of tests

$9 \quad r \quad=$ distance from the center of the column

$10 \quad r_{c}=$ column radius

$11 \quad r_{q}=$ distance between the center of the column and the point of application of load

$12 \quad V \quad=$ vertical load acting on the slab-column connection

$13 V_{\exp }=$ vertical load applied to the slab-column connection at peak moment

$14 \quad V_{k}=$ vertical load acting on the slab-column connection at load step $k$

$15 V_{\text {pred }}=$ predicted vertical load acting on the slab-column connection at peak moment

$16 \quad V_{R} \quad=$ punching shear resistance (without unbalanced moment)

$17 v_{R}(s)=$ shear resistance per unit length

$18 \gamma_{f}=$ contribution of flexure mechanism to the total moment

$19 \gamma_{f \text {.pred }}=$ predicted contribution of flexure mechanism to the total moment

$20 \gamma_{v}=$ contribution of eccentric shear force mechanism to the total moment

$21 \Delta \varphi \quad=$ angle of a slab sector

$22 \Delta r \quad=$ distance from column face

$23 \Delta_{L} \quad=$ slab vertical displacement (or deflection) due to lateral loads

$24 \quad \Delta_{V} \quad=$ slab vertical displacement (or deflection) due to vertical loads 
$1 \Delta_{V+L}=$ slab vertical displacement (or deflection) due to combined vertical and lateral loads

$2 \Delta_{\max }=$ maximum local slab vertical displacement (or deflection)

$3 \Delta_{\min }=$ minimum local slab vertical displacement (or deflection)

$4 \quad \rho \quad=$ hogging (top) flexural reinforcement ratio

$5 \quad \rho^{\prime}=$ sagging (bottom) flexural reinforcement ratio

$6 \varphi=$ angle with respect to the bending axis

$7 \quad \psi(\varphi)=$ local slab with respect to the bending axis

$8 \psi_{c o l}=$ contribution of column deformation to the interstory drift

$9 \quad \psi_{\max }=$ maximum slab rotation

$10 \psi_{\text {max.exp }}=$ maximum measured slab rotation at peak moment

$11 \psi_{\text {max.pred }}=$ maximum predicted slab rotation at peak moment

$12 \psi_{\min }=$ minimum slab rotation

$13 \psi_{s c c}=$ contribution of slab deformation to the interstory drift (connection rotation)

$14 \psi_{\text {scc.defl }}=$ connection rotation defined on the basis of deflections

$15 \psi_{\text {scc.exp }}=$ measured connection rotation at peak moment

$16 \psi_{\text {scc.pred }}=$ predicted connection rotation at peak moment

$17 \psi_{\text {scc.rot }}=$ connection rotation defined on the basis of rotations

$18 \psi_{s t}=$ interstory drift rotation

$19 \psi_{v}=$ slab rotation due to vertical load 